\title{
A NOVEL TODIM BASED ON PROSPECT THEORY TO SELECT GREEN SUPPLIER WITH Q-RUNG ORTHOPAIR FUZZY SET
}

\author{
Xiaoli TIAN ${ }^{1}$, Meiling NIU ${ }^{2}$, Weike $\mathrm{ZHANG}^{3^{*}}$, Lanhao $\mathrm{LI}^{4}$, \\ Enrique HERRERA-VIEDMA ${ }^{5,1 \#}$ \\ ${ }^{1}$ School of Business Administration, Southwestern University of Finance and Economics, \\ 610074 Chengdu, China \\ ${ }^{2}$ School of Public Finance and Taxation, Central University of Finance and Economics, \\ 100081 Beijing, China \\ ${ }^{3}$ School of Public Administration, Sichuan University, 610064 Chengdu, China \\ ${ }^{4}$ Viterbi School of Engineering, University of Southern California, CA90089 Los Angeles, United States \\ ${ }^{5}$ Andalusian Research Institute in Data Science and Computational Intelligence (DaSCI), \\ University of Granada, 18071 Granada, Spain
}

Received 25 June 2019; accepted 19 April 2020

\begin{abstract}
Green supply chain has developed rapidly due to the advocacy of ecological civilization, and choosing a proper green supplier is a crucial issue. Considering the fuzziness of evaluation information and the psychological states of decision makers (DMs) in selecting process, a novel TODIM based on prospect theory with q-rung orthopair fuzzy set (q-ROFS) is proposed. The novel TODIM concerns both the perceived transformed probability weighting function and the differences in risk attitudes. A new distance, which concerns the herd mentality, is carried out to measure the perceived difference of the q-ROFS. Besides, a new systematic evaluation index system, named as PCEM (Product, Cooperation ability, Environment, Market), has been established. A case related to pork supplier companies is presented and fully demonstrates the effectiveness of the novel TODIM when compared with the extended one, the intuitionistic fuzzy TODIM, the Pythagorean fuzzy TODIM as well as the TOPSIS with q-ROFS. Finally, a series of comparative analyses illustrate the advantages of the proposed TODIM.
\end{abstract}

Keywords: TODIM, prospect theory, q-rung orthopair fuzzy set, green supplier selection.

JEL Classification: D21, D81, D91, M21.

\section{Introduction}

With public awareness increased, the researches related to environmental management and supply chain have emerged. Environmental management was incorporated into the supply chain selection system as early as the 1990s (Klassen, 1993). The concept of the green supply

${ }^{\star}$ Corresponding author. E-mail: zhangwk@scu.edu.cn

\#Corresponding author. E-mail: viedma@decsai.ugr.es

Copyright (C) 2020 The Author(s). Published by Vilnius Gediminas Technical University

This is an Open Access article distributed under the terms of the Creative Commons Attribution License (http://creativecommons. org/licenses/by/4.0/), which permits unrestricted use, distribution, and reproduction in any medium, provided the original author and source are credited. 
chain was also born in that period, and it plays a significant role in the environmentallyfriendly society. Now, environmentally-friendly products are highly promoted by customers and governments. In 2017, President Xi put forward the concept of green governance, and pointed out that "Lucid waters and lush mountains are invaluable assets". Concerning the ecological environment and economic development, the green supply chain takes the leading role to impel companies to carry out more green plans in the manufacture and delivery processes. Choosing the most appropriate green supplier is a critical issue during the green supply chain processes. However, all aspects need to be considered, and the evaluation process is the heart of this matter. Thus, a group of studies focuses on the evaluation process.

The number of researches exploring the green supplier selection problem has increased considerably in recent years. For example, the analytic hierarchy process (AHP) is used to evaluate the importance of selected criteria and the performance of green suppliers (Tam \& Tummala, 2001), which contributes to saving the time of decision. Kang et al. (2012) applied the analytic network process (ANP) by considering the interdependencies among critical factors in the green supplier selection process, which gives more systematic analysis. However, some researchers find that it is difficult to obtain reliable results from these studies based on a single model with the increasing complexity of the green supplier selection problem. Therefore, more complicated models are proposed, such as the modified multiplicative AHP (Yu \& Hou, 2016), the WASPAS (Yazdani et al., 2016), the fuzzy TOPSIS (Fallahpour et al., 2017), the integrated fuzzy AHP-VIKOR (Awasthi et al., 2018), the DEMATEL-ANP (Chatterjee et al., 2018).

Although many uncertain aspects of green supplier selection problem have been evaluated and measured properly with the improvement of methodology, however, how to select a suitable green supplier is determined by the decision makers (DMs), and the selection results are largely affected by the feelings of them. Hence, as one of the most important factors in the qualitative assessment of green suppliers, the psychological influences of DMs had been neglected until some scholars have adopted the TODIM (an acronym for Portuguese Interactive and Multimedia Decision Making) to solve this problem in the last few years. It is a conventional multi-criteria decision making (MCDM) with the pairwise comparison of alternatives based on prospect theory (PT) which reflects the behaviors of DMs by using the gains or losses and the transformed weighting function (Gomes \& Lima, 1992). Based on this point, the results obtained by TODIM are more reliable and reflect more psychological influences of DMs on the decision results. Nevertheless, the traditional TODIM only tackles the problem with crisp number. It fails to describe the uncertainty of DMs and is also limited by the difficulty in giving accurate judgments. This dilemma has also been noticed by many researchers, and they integrated various fuzzy sets into TODIM.

Krohling et al. (2013) firstly extended the original TODIM to the intuitionistic fuzzy set (IFS) (Atanassov, 1986) which describes evaluation information by a membership function and a non-membership function. Moreover, the membership and non-membership degrees could be an interval number rather than a crisp number, which is represented by intervalvalued intuitionistic fuzzy set (IV-IFS) (Atanassov \& Gargov, 1989). Hence, interval-valued intuitionistic fuzzy TODIM was developed (Mishra \& Rani, 2018). To effectively address a 
wider range of evaluation information, the Pythagorean fuzzy set (PFS) (Yager, 2013), which satisfies the situation that the square sum of its membership degree and non-membership degree does not exceed 1, is adopted by many researchers to express the complex fuzzy information. Thus, Pythagorean fuzzy TODIM is given (Ren et al., 2016; Liang et al., 2019). To handle the MCDM problems with hybrid information, Fan and Zhang (Fan et al., 2013) proposed an extended TODIM by using three formats of attribute values, including the interval numbers, the triangular fuzzy numbers, and the trapezoidal fuzzy numbers, to express the gains or losses.

However, IFS, PFS, and other extensions based on them have a narrow range of applications because they must meet strict conditions for membership and non-membership degrees (P. D. Liu \& J. L. Liu, 2018). Besides, they are subject to the situation that the exponentiations of membership and non-membership degrees is one or two. On the contrary, qrung orthorpair fuzzy set (q-ROFS) is known as a crucial way to solve these constraints and express multifarious information. The constraint is that the sum of $q$-th power of membership degree and $q$-th power of non-membership degree does not exceed one (Yager, 2017). Apparently, the IFS and PFS are merely special cases of q-ROFS. Therefore, q-ROFS is highly and more available to deal with fuzziness and ambiguity of decision-making problems in the real world. It can express a wider range of fuzzy information. To most importantly, it is more general to express the evaluation information for objectives. Also, the advantages of it can offset the outcome of different methods leading to different results. Therefore, this paper uses q-ROFS as the basic evaluation information in TODIM.

Although, some previous studies have paid attention to combine TODIM with the q-ROFS (Wang \& Li, 2018; Xu et al., 2018), seldom of them have considered the different attitudes of DMs on gains or losses and the transformed weighting function perceived by DMs in the real decision-making situation. In other words, the existing TODIM with q-ROFS is not based on the original PT, and we conclude this type of drawbacks as follows: (i) TODIM is derived from PT and presents the core idea of PT by the dominance function, whereas, most existing researches about TODIM show that the risk attitudes work on the product of relative weight and the perceived gains or losses through the square root of the dominance function, which does not accord with the classical PT. Actually, in classical PT, the risk attitudes only work on the gains or losses according to the value function and do not work on the weight information (Tian et al., 2019; Liang et al., 2018; Qin et al., 2015). (ii) In the current studies about TODIM, the objective probability is used to calculate the relative weight, whereas the perceived transformed probability weighting function, which is an essential part of PT, is ignored. Hence, in this paper, we are dedicated to adopting the framework of modified TODIM by Tian et al. (2019), which comprehensively explained the core idea of PT, to explore the selection of green supplier problem.

The contributions of this paper are as follows: (i) we construct a novel TODIM with q-ROFS which is a more versatile tool to deal with uncertain information. This novel TODIM is based on the classical PT, considering both the perceived transformed probability weighting function and the different risk attitudes of DMs. (ii) we have introduced a new distance based on the herd mentality to describe the choices of hesitant people. (iii) we 
use this novel TODIM to solve green supplier selection problems and propose a systematic construction of the decision index system named as PCEM (Product, Cooperation ability, Environment, Market). This system can be used for various green supplier problems, which shows excellent versatility. These findings are critical because their effectiveness is very beneficial in solving complicated MCDM problems, and they also encourage more researchers to focus on the psychological factors of this field.

The remainder of the paper is organized as follows: Section 1 analyses the common criteria which are of great need in the green supplier selection process and builds a general index system named PCEM for green supplier selection. Section 2 introduces the basic concepts and algorithms, including the q-ROFS and the classic TODIM, which is the fundamental framework of this paper. Section 3 proposes a new distance measurement method, which considers herd mentality influence. Also, in this section, the process of novel TODIM with q-ROFS is presented. In Section 4, a case study is provided. Section 5 shows the advantages of the proposed method by various comparisons. The conclusions and future works are pointed out in last Section.

\section{Analysis about decision-making criteria used by the green supplier}

For companies, choosing green suppliers is critical, especially when people are increasingly concerned about the impacts of the environment. As so many people do not aware that the geographic distance will affect the investment option of venture capital (Tian et al. 2020), selecting a proper supplier is also a complex procedure, and it requires the DMs to comprehensively consider all the aspects. Traditional approaches have considered many criteria in green supplier selection problems, such as cost-profitability, economic-environment-society, as well as the external-internal criteria standard. To specifically describe the topic of green supplier selection, a summary of the ten most cited articles in the ISI Web of Science journal in early 2019 has been selected and listed in Table 1.

According to Table 1 and the top-cited literature review on green supplier selection, we discover that one of the challenges in the green supplier selection process lies in how to establish a suitable and effective index system that is heavily influenced by the purpose of selection. For example, Shaw et al. (2012) used indicators of emissions of greenhouse gases to stress carbon emission issues in the green supply chain. Hsu and $\mathrm{Hu}$ (2009) mentioned $\mathrm{R} \& \mathrm{D}$ management as an indicator to emphasize hazardous substance management. Existing researches only focus on one specific aspect of green supplier selection issues. That is to say, the existing index systems are not universal in this field. Concerning the growing attention on environment protection, there is an urgent need to develop a more versatile and more robust index system. Therefore, in this paper, we are dedicated to establishing a general index system named as PCEM (Seen in Table 2 ) by summarizing indicators widely used in various literature (Please refer to Table 1 for the literature). 
Table 1. The top ten cited articles in green supplier selection in 2019

\begin{tabular}{|c|c|c|c|}
\hline Author(s) & Selection Criteria & Method & Purpose \\
\hline $\begin{array}{l}\text { Buyukozkan } \\
\text { and Cifci } \\
(2012)\end{array}$ & $\begin{array}{l}\text { (1) Organization } \\
\text { (2) Financial performance } \\
\text { (3) Service quality } \\
\text { (4) Technology } \\
\text { (5) Green competencies }\end{array}$ & $\begin{array}{l}\text { Fuzzy } \\
\text { DEMTEL } \\
\text { Fuzzy ANP } \\
\text { Fuzzy TOPSIS }\end{array}$ & $\begin{array}{l}\text { Consider the qualitative and } \\
\text { quantitative components in } \\
\text { the green supplier selection } \\
\text { process. }\end{array}$ \\
\hline $\begin{array}{l}\text { Lee et al. } \\
(2009)\end{array}$ & $\begin{array}{l}\text { (1) Quality } \\
\text { (2) Technology capability } \\
\text { (3) Pollution control } \\
\text { (4) Environmental management } \\
\text { (5) Green product } \\
\text { (6) Green competencies }\end{array}$ & $\begin{array}{l}\text { Fuzzy AHP } \\
\text { Fuzzy-extended } \\
\text { AHP }\end{array}$ & $\begin{array}{l}\text { Propose a hierarchy to } \\
\text { evaluate the importance of the } \\
\text { criteria and the performance } \\
\text { of green suppliers. }\end{array}$ \\
\hline $\begin{array}{l}\text { Min and } \\
\text { Galle } \\
(2001)\end{array}$ & $\begin{array}{l}\text { (1) Environmental liability and } \\
\text { penalty } \\
\text { (2) A supplier's environmental } \\
\text { commitment } \\
\text { (3) Environmental cost }\end{array}$ & $\begin{array}{l}\text { Hypothesis } \\
\text { Testing } \\
\text { Factor Analysis }\end{array}$ & $\begin{array}{l}\text { Identify the variables that } \\
\text { influence the implementation } \\
\text { of green purchasing and } \\
\text { supplier selection. }\end{array}$ \\
\hline $\begin{array}{l}\text { Shaw et al. } \\
(2012)\end{array}$ & $\begin{array}{l}\text { (1) Cost } \\
\text { (2) Quality } \\
\text { (3) Lead time } \\
\text { (4) Emissions of greenhouse gases } \\
\text { (5) Demand }\end{array}$ & $\begin{array}{l}\text { Fuzzy-AHP, } \\
\text { Fuzzy multi- } \\
\text { objective linear } \\
\text { programming }\end{array}$ & $\begin{array}{l}\text { Address the carbon emission } \\
\text { issue to the supplier selection } \\
\text { criteria to select appropriate } \\
\text { suppliers. }\end{array}$ \\
\hline $\begin{array}{l}\text { Kuo et al. } \\
(2010)\end{array}$ & $\begin{array}{l}\text { (1) Service } \\
\text { (2) Cost } \\
\text { (3) Environment } \\
\text { (4) Quality } \\
\text { (5) Delivery } \\
\text { (6) Corporate social responsibility }\end{array}$ & $\begin{array}{l}\text { ANN } \\
\text { DEA } \\
\text { ANP }\end{array}$ & $\begin{array}{l}\text { Develop a new model called } \\
\text { ANN-MADA hybrid method } \\
\text { to evaluate the selection of } \\
\text { green suppliers. }\end{array}$ \\
\hline $\begin{array}{l}\text { Hsu and } \mathrm{Hu} \\
(2009)\end{array}$ & $\begin{array}{l}\text { (1) Procurement management } \\
\text { (2) R\&D management } \\
\text { (3) Process management } \\
\text { (4) Incoming quality control } \\
\text { (5) Management system }\end{array}$ & ANP & $\begin{array}{l}\text { Address the hazardous } \\
\text { substance management into } \\
\text { the green supplier selection } \\
\text { process. }\end{array}$ \\
\hline $\begin{array}{l}\text { Kannan et al. } \\
(2014)\end{array}$ & $\begin{array}{l}\text { (1) Cost } \\
\text { (2) Quality } \\
\text { (3) Delivery } \\
\text { (4) Technology capability } \\
\text { (5) Environmental competency } \\
\text { (6) Financial performance }\end{array}$ & $\begin{array}{l}\text { Fuzzy } \\
\text { DEMATEL } \\
\text { Fuzzy AHP } \\
\text { Fuzzy TOPSIS }\end{array}$ & $\begin{array}{l}\text { Propose an integrated model } \\
\text { to select the best green } \\
\text { supplier by considering } \\
\text { the limited capacity, other } \\
\text { constraints as well as the } \\
\text { expert opinion. }\end{array}$ \\
\hline $\begin{array}{l}\text { Buyukozkan } \\
\text { and Cifci } \\
(2011)\end{array}$ & $\begin{array}{l}\text { (1) Organization } \\
\text { (2) Financial performance } \\
\text { (3) Service quality } \\
\text { (4) Technology } \\
\text { (5) Social responsibility and } \\
\text { environmental competencies }\end{array}$ & Fuzzy AHP & $\begin{array}{l}\text { Novel method considering } \\
\text { incomplete preference to } \\
\text { select suppliers for supply } \\
\text { chains. }\end{array}$ \\
\hline $\begin{array}{l}\text { Hsu et al. } \\
\text { (2013) }\end{array}$ & $\begin{array}{l}\text { (1) Planning } \\
\text { (2) Implementation } \\
\text { (3) Management }\end{array}$ & DEMATEL & $\begin{array}{l}\text { Address the carbon } \\
\text { management in green supply } \\
\text { chain to select best green } \\
\text { supplier who are capable of } \\
\text { having competence in carbon } \\
\text { management. }\end{array}$ \\
\hline
\end{tabular}


Table 2. Evaluation index system of green supplier selection (PCEM)

\begin{tabular}{|l|l|l|}
\hline \multicolumn{1}{|c|}{ Aspect } & \multicolumn{1}{|c|}{ Criteria/Definition } & \multicolumn{1}{c|}{ References } \\
\hline $\begin{array}{l}\text { Product } \\
(P)\end{array}$ & $\begin{array}{l}P_{1}: \text { Interest } \\
P_{2}: \text { Quality } \\
P_{3}: \text { Service }\end{array}$ & $\begin{array}{l}\text { Bai and Sarkis (2010a; 2010b) } \\
\text { Lee et al. (2009); Kuo et al. (2010); Zhang et al. } \\
(2003) ; \text { Kuo et al. (2010); Bala et al. (2008); }\end{array}$ \\
\hline $\begin{array}{l}\text { Cooperation } \\
\text { ability } \\
(C)\end{array}$ & $\begin{array}{l}C_{1}: \text { Management ability } \\
C_{2}: \text { innovation ability }\end{array}$ & $\begin{array}{l}\text { Humphreys et al. (2006); Hsu and Hu (2009) } \\
\text { Chiou et al. (2011); Bin and Hong-jun (2010) } \\
\text { Buyukozkan and Cifci (2011, 2012); Lee et al. } \\
\text { (2009) }\end{array}$ \\
\hline $\begin{array}{l}\text { Environment } \\
(E)\end{array}$ & $\begin{array}{l}E_{1}: \text { Dechnology } \\
E_{2}: \text { Environmental Competences }\end{array}$ & $\begin{array}{l}\text { Awasthi et al. (2010); Humphreys et al. (2006) } \\
\text { Grisi et al. (2010); Humphreys et al. (2006) } \\
\text { Lee et al. (2009); Humphreys et al. (2006) }\end{array}$ \\
\hline $\begin{array}{l}E_{3}: \text { Green image } \\
(M)\end{array}$ & $M_{1}:$ Financial Performance \\
$M_{2}:$ Green market share & $\begin{array}{l}\text { Buyukozkan and Cifci (2011, 2012) } \\
\text { Awasthi et al. (2010); Humphreys et al. (2006) }\end{array}$ \\
\hline
\end{tabular}

\section{(1) Product $(P)$}

Product is the primary and most essential part to select a suitable supplier. There is no doubt that better products are often more competitive in the market. It contains interest $\left(P_{1}\right)$, quality $\left(P_{2}\right)$, and service $\left(P_{3}\right)$. Kuo et al. (2010) pointed out the price, quality and service were the top three indicators for evaluating a suitable green supplier, because these indicators, especially quality and service, can comprehensively reflect the internal value of the product. However, according to Bai and Sarkis (2010a, 2010b), supplier of high interest has a better chance of achieving higher joint performance. In this paper, interest $\left(P_{1}\right)$, calculated by the net income divided by unit cost, is used to effectively measure the profitability of the company other than the price. Quality $\left(P_{2}\right)$ refers to the ability to improve product quality, including quality-related certificates and quality management systems. Moreover, according to Bala et al. (2008), service $\left(P_{3}\right)$ considers the service attitude, after service, as well as the willingness to solve conflicts.

\section{(2) Cooperation ability $(C)$}

Trapp and Sarkis (2016) introduced that the choice of supplier was closely related to the cooperation ability, and it could make a real difference in the strong competence market. Many studies take the company management as the cooperation ability. Actually, the management ability $\left(C_{1}\right)$ is only one aspect of it. It focuses on the effectiveness of procurement management and process management. Koplin et al. (2007) found that top-notch suppliers typically established a vertical supplier structure to work effectively, and a good supplier chain helped substantially mitigate the potential risks.

Besides, factors such as innovation ability $\left(C_{2}\right)$ and technology ability $\left(C_{3}\right)$ also need to be considered. Innovation ability $\left(C_{2}\right)$ is an important aspect to indicate a company's ability, and it usually directly gives rise to the changes of the customers' choice. Chen et al. (2006) pointed out that the innovation process could differentiate products from different companies, and contribute to lower production costs, which is closely related to the competitive advantage of enterprises. In other words, companies with higher innovation capabilities tend to be favored. They are generally more likely to upgrade and update their products in a greener way, and are more acceptable by customers. As for technology $\left(C_{3}\right)$, it refers to the 
revolution capacity and the degree of automation. Buyukozkan and Cifci (2011) concluded it as one of the most essential factors to maintain environment improvements and product competence, which is adopted by the majority of the green supplier selection system.

(3) Environment $(E)$

The environment is the most crucial part of green supplier selection because green products often carry environmental labels. Chen et al. (2014) mentioned that environment was the key element for the green supply chain. This aspect includes three criteria: environment $\left(E_{1}\right)$, environmental competences $\left(E_{2}\right)$, and green image $\left(E_{3}\right)$, respectively. Design for environment $\left(E_{1}\right)$ contains five vital steps, including recycling, reuse, re-manufacture, disassembly, and disposal. Superior suppliers consider every step to maximize their benefits and realize sustainable development described by Awasthi et al. (2010). Moreover, environmental competence $\left(E_{2}\right)$ emphasizes green material and green technology, which helps to make a deeper impression on the product. The deeper the company's impression of environmental protection, the greater the product sales will be. However, the green image $\left(E_{3}\right)$ is an abstract criterion and is usually neglected by customers. Actually, it primarily affects the final choice of customers. Hence, it is necessary to be considered.

(4) Market (M)

Awasthi et al. (2010) pointed out that marketing factors would be of great importance. The market mainly reflects by financial performance $\left(M_{1}\right)$ and green market share $\left(M_{2}\right)$. Financial performance $\left(M_{1}\right)$ shows the financial ability of the supplier. Buyukozkan and Cifci (2011) believed that the financial situation and the stability of funds were the most fundamental issues for the sustainability of supplier companies. Besides, the green market share $\left(M_{2}\right)$ can lead to differences between green suppliers, because the green supply chain has a certain degree of concentration for customers with green purchasing habits. The crucial role of the green market share $\left(M_{2}\right)$ in the green supply chain has also been demonstrated by many researchers who take the retention of customers with green purchasing habits as a significant factor.

From the above retrospect and explanation, green suppliers pay very close attention to four aspects: product, cooperation ability, environment, as well as market. Moreover, PCEM obtained from those extensive researches has excellent versatility.

\section{Basic concepts and algorithms}

In this section, we briefly review the concepts of q-ROFS and classical TODIM. They are the fundamental line of this paper and have excellent advantages in handling fuzzy information and MCDM problems, respectively.

\subsection{Q-rung orthopair fuzzy set}

Compared with IFS and PFS, q-ROFS (Yager, 2017) is developed to express a broader range of fuzzy information. They all consist of two parts: support $(u)$ and opposition $(v)$. Differently, in q-ROFS, the sum of the $q$-th power of the membership degree and the $q$-th power 
of the non-membership degree is no more than one, while, in IFS and PFS, $q=1$ and $q=$ 2 respectively. Obviously, q-ROFS is a more general one. In other words, IFS and PFS are just special cases of q-ROFS. Hence, in this paper, we use q-ROFS to express the evaluation information.

A q-ROFS, in a finite universe of discourse $X$, is given by

$$
A=\left\{<x_{A}, \mu_{A}(x), v_{A}(x)>\mid x \in X\right\},
$$

where $\mu_{A}(x) \in[0,1]$ denotes the degree of membership and $v_{A}(x) \in[0,1]$ means the degree of non-membership of the element $x \in X$ belonging to the set $A$, respectively, with the condition that $0 \leq \mu_{A}(x)^{q}+v_{A}(x)^{q} \leq 1 . \alpha=\left(\mu_{\alpha}(x), v_{\alpha}(x)\right)$ is called q-rung orthopair fuzzy number (q-ROFN). The degree of hesitancy is $\pi_{A}(x)=\sqrt[q]{1-\left(\mu_{A}(x)\right)^{q}-\left(v_{A}(x)\right)^{q}}$. According to (1), a q-ROFS can easily degenerate into IFS or PFS by setting the $q=1$ and $q=2$ respectively.

To compare the difference between two q-ROFNs $\alpha_{A}=\left(\mu_{A}, v_{A}\right)$ and $\alpha_{B}=\left(\mu_{B}, v_{B}\right)$, score function $S\left(\alpha_{i}\right)$ and accuracy function $H\left(\alpha_{i}\right)$ are presented as:

$$
\begin{aligned}
& S\left(\alpha_{i}\right)=\mu_{i}^{q}-v_{i}^{q} ; \\
& H\left(\alpha_{i}\right)=\mu_{i}^{q}+v_{i}^{q} .
\end{aligned}
$$

According to the equations above, we can select a reasonable result by the following comparison equations:

(1) If $S\left(\alpha_{A}\right)>S\left(\alpha_{B}\right)$, then $\alpha_{A}>\alpha_{B}$;

(2) If $S\left(\alpha_{A}\right)<S\left(\alpha_{B}\right)$, then $\alpha_{A}>\alpha_{B}$;

(3) If $S\left(\alpha_{A}\right)=S\left(\alpha_{B}\right)$, then

1) If $H_{A}>H_{B}$, then $\alpha_{A}>\alpha_{B}$;

2) If $H_{A}<H_{B}$, then $\alpha_{A}<\alpha_{B}$;

3) If $H_{A}=H_{B}$, then $\alpha_{A}=\alpha_{B}$.

\subsection{Classical TODIM}

Let $A=\left\{a_{1}, a_{2}, \cdots, a_{n}\right\}$ be a finite set of alternatives, $C=\left\{c_{1}, c_{2}, \cdots, c_{m}\right\}$ be a finite set of criteria, $\omega=\left\{\omega_{1}, \omega_{2}, \cdots, \omega_{m}\right\},\left(\sum_{j=1}^{m} \omega_{j}=1\right)$ be the weighting vector of criteria, and decision matrix be the $X=\left[x_{i j}\right]_{n \times m}$. Then, the procedure of classical TODIM (Gomes \& Lima, 1991) is shown as follows:

Step 1: Normalize the decision matrix $X=\left[x_{i j}\right]_{n \times m}$ into $V=\left[v_{i j}\right]_{n \times m}$, according to the cost criterion and benefit criterion, $i \in N, j \in M$ :

$$
v_{i j}= \begin{cases}x_{i j}, & c_{j} \text { is benefit criterion } \\ -x_{i j}, & c_{j} \text { is cost criterion }\end{cases}
$$

Step 2: Obtain the relative weight $\omega_{j r}$ of criterion $c_{j}(j=1,2, \cdots, m)$ : 


$$
\omega_{j r}=\frac{\omega_{j}}{\omega_{r}},
$$

where $\omega_{r}=\max \left\{\omega_{j} \mid j=1,2, \cdots, m\right\} . \omega_{j}$ and $\omega_{r}$ are the original weights of criteria $c_{j}$ and $c_{r}$ correspondingly, and $c_{r}$ is the reference criterion.

Step 3: Calculate the relative dominance degree of each alternative $a_{i}$ over the rest of the alternative $a_{k}(k=1,2, \cdots, n, k \neq i)$ regarding $c_{j}$.

$$
\Phi_{j}\left(a_{i}, a_{k}\right)= \begin{cases}\sqrt{\omega_{j r}\left(v_{i j}-v_{k j}\right) / \sum_{j=1}^{m} \omega_{j r}} & \text { if } v_{i j}>v_{k j} \\ 0 & \text { if } v_{i j}=v_{k j} . \\ -\frac{1}{\theta} \sqrt{\left(\sum_{j=1}^{m} \omega_{j r}\right)\left(v_{i j}-v_{k j}\right) / \omega_{j r}} & \text { if } v_{i j}<v_{k j}\end{cases}
$$

The parameter $\theta$ denotes the attenuation factor of the losses.

Step 4: Acquire the dominance degree $\delta\left(a_{i}, a_{k}\right)$, which is affected by the sum up of the alternative $a_{i}$ over the rest of the alternative $a_{k}(k=1,2, \cdots, n, k \neq i)$ :

$$
\delta\left(a_{i}, a_{k}\right)=\sum_{j=1}^{m} \Phi_{j}\left(a_{i}, a_{k}\right) .
$$

Step 5: Get the overall dominance degrees $\eta\left(a_{i}\right)$ :

$$
\eta\left(a_{i}\right)=\frac{\sum_{k=1}^{n} \delta\left(a_{i}, a_{k}\right)-\min _{i}\left\{\sum_{k=1}^{n} \delta\left(a_{i}, a_{k}\right)\right\}}{\max _{i}\left\{\sum_{k=1}^{n} \delta\left(a_{i}, a_{k}\right)\right\}-\min _{i}\left\{\sum_{k=1}^{n} \delta\left(a_{i}, a_{k}\right)\right\}} .
$$

Step 6: Rank the alternatives according to the overall dominance degree of each alternative $\eta\left(a_{i}\right)$. The bigger the $\eta\left(a_{i}\right)$ is, the better the alternative $a_{i}$ will be:

$$
a_{i} \succ a_{i} \Leftrightarrow \eta\left(a_{i}\right)>\eta\left(a_{i^{\prime}}\right) .
$$

\section{Novel TODIM with q-rung orthopair fuzzy set}

Information fusion is an essential part in the decision-making process. In addition, distance is an important way to integrate fuzzy information. Firstly, in this section, we will propose a new distance by considering the influence of herd mentality. Then, the novel TODIM with q-ROFS is constructed. Finally, an extension of classical TODIM with q-ROFS is presented here.

\subsection{Limitations of the existing distance measure}

Existing distance measures can be divided into two groups. The first group only considers the influence of support $(\mu)$ and opposition $(v)$. For example, the measurement of normalized 
Hamming distance $d_{1}(A, B)=\frac{1}{2 n} \sum_{j=1}^{n}\left(\left|\mu_{A}-\mu_{B}\right|+\left|v_{A}-v_{B}\right|\right)$ only covers membership $(\mu)$ and non-membership $(v)$. Moreover, the second group includes the degree of hesitancy, such as the advanced Euclidean distance $d_{2}(A, B)=\sqrt{\frac{1}{2 n} \sum_{j=1}^{n}\left[\left(\mu_{A}-\mu_{B}\right)^{2}+\left(v_{A}-v_{B}\right)^{2}+\left(\pi_{A}-\pi_{B}\right)^{2}\right]}$ (Szmidt \& Kacprzyk, 2000). Du and Hu (2017) concluded that the ranking of orthopairs may differ from the distance equation. With the escalation complexity of decision-making information, the influence of psychological factors on the decision-making process can no longer be ignored in modern society when people make his/her choice with hesitation. Therefore, it is reasonable to combine the psychology of DM with distance, and we also offer a new perspective for distance measure.

\subsection{New perspective of distance measure}

Peng et al. (2018) introduced the herd mentality in score function. However, the distance is instrumental to the comparison of fuzzy information. The accuracy of distance measurement has a profound effect on the relative dominance $(\Phi)$ which may directly change the final choice. In addition, distance is greatly influenced by such a herd mentality. That is, people often hesitate and change their minds in the process of decision making. For example, when a $\mathrm{DM}$ is hesitant, his/her decision may be vacillated by the value of the support $(\mu)$ and opposition $(v)$. Therefore, a new distance measure is first proposed to consider the herd mentality influence established in the form of the properties of $S$ curve function $f(x)=\frac{e^{x}}{e^{x}+1}$, and then
the influence of herd mentality is described (Peng et al., 2018).

Let $\alpha_{A}=\left(\mu_{A}, v_{A}\right)$ and $\alpha_{B}=\left(\mu_{B}, v_{B}\right)$ be two q-ROFNs, and $X=\left\{x_{1}, x_{2}, \cdots, x_{n}\right\}$ be a universe of discourse. The new distance measure $d_{R}(\cdot)$ between $A$ and $B$ is given by:

where $p \geq 1$.

$$
\begin{aligned}
& d_{R}(A, B)=\left(\frac{1}{3}\left|\mu_{A}-\mu_{B}\right|^{P}+\frac{1}{3}\left|v_{A}-v_{B}\right|^{P}+\frac{1}{3}\left|\frac{v_{A}-v_{B}}{\mu_{A}-\mu_{B}}\left(\pi_{A}^{\prime}-\pi_{B}^{\prime}\right)^{P}\right|\right)^{1 / P} ; \\
& \pi_{i}{ }^{\prime}=\left|\left(\frac{e^{u_{i}^{q}-v_{i}^{q}}}{e^{u_{i}^{q}-v_{i}^{q}}+1}-\frac{1}{2}\right)\left(1-\left(\mu_{i}(x)\right)^{q}-\left(v_{i}(x)\right)^{q}\right)\right| .
\end{aligned}
$$

When $p=1$, it is the Hamming distance between $A$ and $B$, that is,

$$
\begin{aligned}
& d_{H}(A, B)=\left(\frac{1}{2}\left|\mu_{A}-\mu_{B}\right|+\frac{1}{2}\left|v_{A}-v_{B}\right|+\left|\frac{v_{A}-v_{B}}{\mu_{A}-\mu_{B}}\left(\pi_{A}^{\prime}-\pi_{B}^{\prime}\right)\right|\right) ; \\
& \pi_{i}{ }^{\prime}=\left|\left(\frac{e^{\mu_{i}-v_{i}}}{e^{\mu_{i}-v_{i}}+1}-\frac{1}{2}\right)\left(1-\left(\mu_{i}(x)\right)-\left(v_{i}(x)\right)\right)\right| .
\end{aligned}
$$

When $p=2$, it is the Euclidean distance between $A$ and $B$, that is,

$$
d_{E}(A, B)=\left(\frac{1}{2}\left|\mu_{A}-\mu_{B}\right|^{2}+\frac{1}{2}\left|v_{A}-v_{B}\right|^{2}+\left|\frac{v_{A}-v_{B}}{\mu_{A}-\mu_{B}}\left(\pi_{A}^{\prime}-\pi_{B}^{\prime}\right)^{2}\right|\right)^{1 / 2} ;
$$




$$
\pi_{i}^{\prime}=\left|\left(\frac{e^{u_{i}^{2}-v_{i}^{2}}}{e^{u_{i}^{2}-v_{i}^{2}}+1}-\frac{1}{2}\right)\left(1-\left(\mu_{i}(x)\right)^{2}-\left(v_{i}(x)\right)^{2}\right)\right| .
$$

Proposition. Let $d_{R}(A, B)$ be the novel distance between two q-ROFs $A=\left(A^{+}, A^{-}\right)$and $B=\left(B^{+}, B^{-}\right)$. Then, there are:

$$
\begin{aligned}
& 0 \leq d_{R}(A, B) \leq 1 ; \\
& d_{R}(A, B)=0, \text { iff } A=B ; \\
& d_{R}(A, B)=d_{R}(B, A) ; \\
& d_{R}(A, C) \leq d_{R}(A, B)+d_{R}(B, C) ;
\end{aligned}
$$

For $C=<C^{+}, C^{-}>$, if $A \leq B \leq C$, then $d_{R}(A, C) \geq d_{R}(A, B) \vee d_{R}(B, C)$.

\subsection{Procedure of novel TODIM with q-rung orthopair fuzzy set}

Let $A=\left(a_{1}, a_{2}, \cdots, a_{n}\right)$ be a finite set of alternatives, $C=\left\{c_{1}, c_{2}, \cdots, c_{m}\right\}$ be the criteria, and $\omega=\left(\omega_{1}, \omega_{2}, \cdots, \omega_{m}\right) \quad\left(\sum_{j=1}^{m} \omega_{j}=1\right)$ be the weighting vector of the corresponding criterion. Then, the decision matrix $X=\left[x_{i j}\right]_{n \times m}$ satisfies the characteristic of the q-ROFS, where $x_{i j}$ denotes the evaluation information of alternative $a_{i}$ over $c_{j}$. After that, the procedure of q-rung orthopair fuzzy TODIM is described step by step as follows:

Step 1: Obtain the normalized decision matrix $P=\left(p_{i j}\right)_{n \times m}$ according to (4).

Step 2: Work out the weighting value $\xi\left(\omega_{j}\right)$ according to the following equation, and the transformed probability weight is acquired by (12):

$$
\xi\left(\omega_{j}\right)=\left\{\begin{array}{l}
\xi^{+}\left(\omega_{j}\right)=\frac{\left(\omega_{j}\right)^{\gamma}}{\left(\left(\omega_{j}\right)^{\gamma}+\left(1-\omega_{j}\right)^{\gamma}\right)^{\frac{1}{\gamma}}}, p_{i j}-p_{k j} \geq 0 \\
\xi^{-}\left(\omega_{j}\right)=\frac{\left(\omega_{j}\right)^{\delta}}{\left(\left(\omega_{j}\right)^{\delta}+\left(1-\omega_{j}\right)^{\delta}\right)^{\frac{1}{\delta}}}, p_{i j}-p_{k j}<0
\end{array},\right.
$$

where $\omega_{j}$ is the weight of $c_{j}$; both $\gamma$ and $\delta$ are the parameters describing the curvature of the weighting function, and they represent the differences in sensitivity reduction in the domain of gains and losses, respectively.

Step 3: Determine the relative weight $\xi^{*}\left(\omega_{j r}\right)$ for $a_{i}$ over $a_{k}$ :

$$
\xi^{*}\left(\omega_{j r}\right)=\frac{\xi\left(\omega_{j}\right)}{\xi\left(\omega_{r}\right)}, r, j \in M, \forall(i, k),
$$

where $\omega_{j}$ and $\omega_{r}$ are the original weights of criteria $c_{j}$ and $c_{r}$ correspondingly. $\xi\left(\omega_{j}\right)$ and $\xi\left(\omega_{r}\right)$ represent the transformed weight calculated by $(12)$, where $\xi\left(\omega_{r}\right)=\max \left\{\xi\left(\omega_{j}\right) \mid j \in M\right\}$.

Step 4: Get the relative dominance of $a_{i}$ over $a_{k}$ under the criterion $c_{j}$ by (14): 


$$
\Phi_{j^{*}}\left(a_{i}, a_{k}\right)= \begin{cases}\xi^{*}\left(d\left(p_{i j}, p_{k j}\right)\right)^{\alpha} / \sum_{j=1}^{m} \xi^{*} & \text { if } p_{i j}>p_{k j} \\ 0 & \text { if } p_{i j}=p_{k j}, \\ -\lambda\left(\sum_{j=1}^{m} \xi^{*}\right)\left(d\left(p_{i j}, p_{k j}\right)\right)^{\beta} / \xi^{*} & \text { if } p_{i j}<p_{k j}\end{cases}
$$

where parameter $\lambda$ denotes the attenuation factor of the losses and $\lambda>0 . d\left(p_{i j}, p_{k j}\right)$ is the distance of $p_{i j}$ and $p_{k j}$, which is calculated by (10).

Step 5: Acquire the dominance degree $\delta\left(a_{i}, a_{k}\right)$ determined by the relative dominance degree of $a_{i}$ over $a_{k}$.

$$
\delta^{\star}\left(a_{i}, a_{k}\right)=\sum_{j=1}^{m} \Phi_{j^{*}}\left(a_{i}, a_{k}\right) .
$$

Step 6: Get the overall dominance degree based on (16):

$$
\eta^{*}\left(a_{i}\right)=\frac{\sum_{k=1}^{n} \delta^{*}\left(a_{i}, a_{k}\right)-\min _{i}\left\{\sum_{k=1}^{n} \delta^{*}\left(a_{i}, a_{k}\right)\right\}}{\max _{i}\left\{\sum_{k=1}^{n} \delta^{*}\left(a_{i}, a_{k}\right)\right\}-\min _{i}\left\{\sum_{k=1}^{n} \delta^{*}\left(a_{i}, a_{k}\right)\right\}} .
$$

Step 7: Rank the alternatives according to the overall dominance degree of each alternative $\eta\left(a_{i}\right)$ and find the optimal one:

$$
a_{i} \succ a_{i^{\prime}} \Leftrightarrow \eta^{*}\left(a_{i}\right)>\eta^{*}\left(a_{i^{\prime}}\right) .
$$

The bigger the $\eta^{*}\left(a_{i}\right)$ is, the better the alternative $a_{i}$ will be.

However, if there is $\eta^{*}\left(a_{i}\right)=\eta^{*}\left(a_{i^{\prime}}\right)$, we should judge again by using the degree of hesitancy in $(11)$, where $\pi^{\prime}\left(p_{i j}\right)=\left|\left(\frac{e^{u_{i j}^{q}-v_{i j}^{q}}}{e^{u_{i j}^{q}-v_{i j}^{q}}+1}-\frac{1}{2}\right)\left(1-\left(\mu_{i j}(x)\right)^{q}-\left(v_{i j}(x)\right)^{q}\right)\right|$.

(1) If $\sum_{j=1}^{n} \pi^{\prime}\left(p_{i j}\right)>\sum_{j=1}^{n} \pi^{\prime}\left(p_{i^{\prime} j}\right)$, then $a_{i} \prec a_{i^{\prime}}$;

(2) If $\sum_{j=1}^{n} \pi^{\prime}\left(p_{i j}\right)<\sum_{j=1}^{n} \pi^{\prime}\left(p_{i^{\prime} j}\right)$, then $a_{i} \succ a_{i^{\prime}}$;

(3) If $\sum_{j=1}^{n} \pi^{\prime}\left(p_{i j}\right)=\sum_{j=1}^{n} \pi^{\prime}\left(p_{i^{\prime} j}\right)$, then $a_{i} \approx a_{i^{\prime}}$.

\subsection{Procedure of extended TODIM with q-rung orthopair fuzzy set}

To show the advantages of the novel TODIM in Section 3.3, we also propose the extended TODIM with q-ROFS.

Step 1: Get the decision matrix $X=\left[x_{i j}\right]_{n \times m}$ and $\omega=\left(\omega_{1}, \omega_{2}, \cdots, \omega_{m}\right)\left(\sum_{j=1}^{m} \omega_{j}=1\right)$, where $x_{i j}$ denotes the evaluation information of $a_{i}$ over $c_{j}$, which satisfies the characteristic of qROFS, and $\omega_{j}$ is the weighting vector of criterion $c_{j}$. Then, normalize the fuzzy decision matrix into $P=\left(p_{i j}\right)_{n \times m}$ based on (4). 
Step 2: Calculate the relative weights $\omega_{j r}$ of criterion $c_{j}(j=1,2, \cdots, m)$ :

where $\omega_{r}=\max \left\{\omega_{j} \mid j=1,2, \cdots, m\right\}$.

$$
\omega_{j r}=\frac{\omega_{j}}{\omega_{r}},
$$

Step 3: Obtain the new distance of $p_{i j}$ over $p_{k j}$ according to (10) and (11), and calculate the dominance degree by comparing possibility index first:

$$
\Phi_{j}^{\prime}\left(a_{i}, a_{k}\right)= \begin{cases}\sqrt{\omega_{j r} d\left(p_{i j}, p_{k j}\right) / \sum_{j=1}^{m} \omega_{j r}} & \text { if } p_{i j}>p_{k j} \\ 0 & \text { if } p_{i j}=p_{k j} . \\ -\frac{1}{\theta} \sqrt{\left(\sum_{j=1}^{m} \omega_{j r}\right)\left(d\left(p_{i j}, p_{k j}\right)\right) / \omega_{j r}} & \text { if } p_{i j}<p_{k j}\end{cases}
$$

The parameter $\theta$ denotes the attenuation factor of the losses.

Step 4: Calculate the dominance degree $\delta^{\prime}\left(a_{i}, a_{k}\right)$ according to (15).

Step 5: Obtain the overall dominance degree, $\eta^{\prime}\left(a_{i}\right)$ on the basis of (16).

Step 6: Rank the alternatives according to the overall dominance degree of each alternative $\eta^{\prime}\left(a_{i}\right)$. The bigger the $\eta^{\prime}\left(a_{i}\right)$ is, the better the alternative $a_{i}$ will be, that is:

$$
a_{i} \succ a_{i^{\prime}} \Leftrightarrow \eta^{\prime}\left(a_{i}\right)>\eta^{\prime}\left(a_{i^{\prime}}\right) .
$$

\section{Case study}

This section conducts a case with pork supplier companies, and the effectiveness of the novel TODIM is fully proved by comparing it with the extended TODIM and extended TOPSIS. Besides, the case is also applied to IFS and PFS to show the advantages of q-ROFS.

\subsection{Background information about the case}

Food safety is a worldwide everlasting topic, and the food supply chain is widely regarded as a vital part of it. Recently, the pork supply chain draws great attention of governments due to the African swine fever (ASF). China is the largest producer of pigs and pork in the world, with about 680 million pigs, and its pork production accounts for more than half of the global production. Since the ASF swept through China, it has reportedly appeared in four northeastern provinces, covering an area of several thousand square kilometers, and 430 million pigs were infected since August 21, 2018, according to Science magazine.

The rapid spread of ASF is attributed to China's special hog breeding patterns. Many pigs are raised by small farms that lack basic bio-safety facilities and measures. Moreover, hormones and pesticides are used inappropriately. Various unqualified feeding procedures can cause residues in pigs. Most importantly, the bad pattern has seriously affected the green ecological environment of the breeding grounds. Consequently, how to develop 
the green supply chain for the pig industry and to realize food safety and environmentally friendly is a win-win topic. Four hog companies are selected to do more detailed investigations based on the systematic evaluation criteria of green suppliers in section 2, including Texong $A_{1}$, Lonshi $A_{2}$, Betensh $A_{3}$, Ulela $A_{4}$. The calculated weights of criteria are $\omega=\left\{\omega_{1}, \omega_{2}, \cdots, \omega_{11}\right\}=\{0.1965,0.1189,0.1297,0.0982,0.0472,0.0483,0.0547,0.0689,0.0352$, $0.1043,0.0981\}$.

\subsection{Screening process by the novel TODIM with q-rung orthopair fuzzy set}

Step 1: After discreet discussion, evaluation information of the four green suppliers is given, and we identify every $x_{i j}$ by judging whether it belongs to the cost criterion and get the corresponding normalized $p_{i j}$ in Table 3 .

Table 3. Evaluation matrix

\begin{tabular}{|c|c|c|c|c|c|c|c|c|c|c|c|}
\hline & $c_{1}$ & $c_{2}$ & $c_{3}$ & $c_{4}$ & $c_{5}$ & $c_{6}$ & $c_{7}$ & $c_{8}$ & $c_{9}$ & $c_{10}$ & $c_{11}$ \\
\hline$A_{1}$ & $(0.82,0.02)$ & $(0.04,0.17)$ & $(0.55,0.30)$ & $(0.74,0.19)$ & $(0.69,0.18)$ & $(0.37,0.63)$ & $(0.78,0.08)$ & $(0.49,0.44)$ & $(0.45,0.31)$ & $(0.21,0.30)$ & $(0.47,0.23)$ \\
\hline$A_{2}$ & $(0.23,0,17)$ & $(0.23,0.44)$ & $(0.43,0.18)$ & $(0.44,0.11)$ & $(0.26,0.41)$ & $(0.59,0.26)$ & $(0.22,0.12)$ & $(0.30,0.32)$ & $(0.42,0.51)$ & $(0.09,0.26)$ & $(0.80,0.03)$ \\
\hline$A_{3}$ & $(0.24,0.46)$ & $(0.52,0.23)$ & $(0.04,0.89)$ & $(0.10,0.26)$ & $(0.14,0.72)$ & $(0.11,0.65)$ & $(0.70,0.20)$ & $(0.03,0.74)$ & $(0.50,0.48)$ & $(0.18,0.24)$ & $(0.89,0.03)$ \\
\hline$A_{4}$ & $(0.49,0.17)$ & $(0.50,0.47)$ & $(0.06,0.68)$ & $(0.04,0.07)$ & $(0.52,0.10)$ & $(0.72,0.15)$ & $(0.08,0.13)$ & $(0.17,0.39)$ & $(0.06,0.40)$ & $(0.53,0.42)$ & $(0.29,0.43)$ \\
\hline
\end{tabular}

Step 2: The transformed probability weight is calculated according to (12), and it shows in Table 4 . Based on the transformed probability weight in Table 4 , the relative weight $\xi^{*}\left(\omega_{j r}\right)$ is calculated by (13), and it reflects the relative values of each transformed weight value.

Table 4. Transformed probability weights

\begin{tabular}{|c|c|c|c|c|c|c|c|c|c|c|c|}
\hline & $c_{1}$ & $c_{2}$ & $c_{3}$ & $c_{4}$ & $c_{5}$ & $c_{6}$ & $c_{7}$ & $c_{8}$ & $c_{9}$ & $c_{10}$ & $c_{11}$ \\
\hline$\xi^{+}(\omega)$ & 0.259 & 0.203 & 0.211 & 0.185 & 0.128 & 0.129 & 0.138 & 0.155 & 0.110 & 0.190 & 0.185 \\
\hline$\xi^{-}(\omega)$ & 0.253 & 0.189 & 0.199 & 0.168 & 0.108 & 0.109 & 0.118 & 0.136 & 0.090 & 0.176 & 0.168 \\
\hline
\end{tabular}

Note: Here $\gamma=0.61, \delta=0.69$ in (12). The values of them are from the experiment conducted by Tversky and Kahneman (1992), and they are used by numerous researchers.

Step 3: The results of the hesitant degree of each position according to (11) are exhibited in Table 5. Then, the new distance between $p_{i j}$ and $p_{k j}$ based on (10) are measured. Here, we just present the result of $D\left(c_{1}\right)$ regarding $c_{1}$.

Table 5. Hesitate degree of possibility index $p_{i j}$

\begin{tabular}{|c|c|c|c|c|c|c|c|c|c|c|c|}
\hline & $c_{1}$ & $c_{2}$ & $c_{3}$ & $c_{4}$ & $c_{5}$ & $c_{6}$ & $c_{7}$ & $c_{8}$ & $c_{9}$ & $c_{10}$ & $c_{11}$ \\
\hline$\pi^{*}\left(A_{1}\right)$ & 0.060 & 0.001 & 0.028 & 0.058 & 0.053 & 0.035 & 0.061 & 0.006 & 0.0135 & 0.004 & 0.0202 \\
\hline$\pi^{*}\left(A_{2}\right)$ & 0.0018 & 0.017 & 0.017 & 0.019 & 0.012 & 0.036 & 0.002 & 0.001 & 0.012 & 0.004 & 0.061 \\
\hline$\pi^{*}\left(A_{3}\right)$ & 0.019 & 0.027 & 0.050 & 0.004 & 0.057 & 0.049 & 0.054 & 0.059 & 0.003 & 0.002 & 0.050 \\
\hline$\pi^{*}\left(A_{4}\right)$ & 0.025 & 0.0040 & 0.053 & $7 \mathrm{E}-05$ & 0.030 & 0.057 & 0.0004 & 0.013 & 0.015 & 0.015 & 0.012 \\
\hline
\end{tabular}




$$
D\left(c_{1}\right)=\left(\begin{array}{ccccc} 
& A_{1} & A_{2} & A_{3} & A_{4} \\
A_{1} & 0 & 0.252 & 0.350 & 0.165 \\
A_{2} & 0.252 & 0 & 0.262 & 0.087 \\
A_{3} & 0.350 & 0.262 & 0 & 0.182 \\
A_{4} & 0.165 & 0.087 & 0.182 & 0
\end{array}\right) .
$$

Step 4: The relative dominance degree of the alternative $A_{1}$ over the others for each criterion is determined by (14), shown in Table 6 .

Table 6. Relative dominance of alternative $A_{1}$

\begin{tabular}{|c|c|c|c|c|c|c|c|c|c|c|c|}
\hline & $c_{1}$ & $c_{2}$ & $c_{3}$ & $c_{4}$ & $c_{5}$ & $c_{6}$ & $c_{7}$ & $c_{8}$ & $c_{9}$ & $c_{10}$ & $c_{11}$ \\
\hline$\Phi^{*}\left(a_{1}, a_{2}\right)$ & 0.041 & 0.021 & 0.013 & 0.016 & 0.018 & -8.480 & 0.018 & 0.011 & 0.006 & -1.674 & -5.187 \\
\hline$\Phi^{*}\left(a_{1}, a_{3}\right)$ & 0.054 & -4.538 & 0.047 & 0.028 & 0.028 & 0.009 & 0.007 & 0.025 & 0.007 & -1.054 & -5.835 \\
\hline$\Phi^{*}\left(a_{1}, a_{4}\right)$ & 0.028 & -6.111 & 0.038 & 0.032 & 0.008 & -11.772 & 0.022 & 0.013 & 0.012 & -4.109 & 0.016 \\
\hline
\end{tabular}

Note: Here $\alpha=0.88, \beta=0.69, \lambda=2.25$ in (14). The values of them are from the experiment conducted by Tversky and Kahneman (1992), and they are used by many researchers. The distance parameter $p$ is 1 , and $q$ is 3 .

Step 5: The dominance degrees of the alternative $A_{i}$ over the others from (15) are shown in Table 7.

Table 7. Prospect dominance degree of $A_{1}$

\begin{tabular}{|c|c|c|}
\hline$\delta^{*}\left(a_{1}, a_{2}\right)$ & $\delta^{*}\left(a_{1}, a_{3}\right)$ & $\delta^{*}\left(a_{1}, a_{4}\right)$ \\
\hline-15.1970 & -11.2232 & -21.8236 \\
\hline
\end{tabular}

Step 6: The overall dominance of each alternative is calculated by (16), and the results are exhibited in Table 8 .

Table 8. Overall dominance

\begin{tabular}{|l|l|l|l|}
\hline$\eta^{*}\left(A_{1}\right)$ & $\eta^{*}\left(A_{2}\right)$ & $\eta^{*}\left(A_{3}\right)$ & $\eta^{*}\left(A_{4}\right)$ \\
\hline 1.0000 & 0.6987 & 0.0000 & 0.3847 \\
\hline
\end{tabular}

Step 7: It is known that there is $\eta^{*}\left(A_{1}\right)>\eta^{*}\left(A_{2}\right)>\eta^{*}\left(A_{4}\right)>\eta^{*}\left(A_{3}\right)$, then, $A_{1} \succ A_{2} \succ A_{4} \succ A_{3}$. The alternative $A_{1}$ is recognized as the best option among the four green suppliers, whereas, $A_{3}$ is regarded as the worst one.

\subsection{Screening process by the extended TODIM with q-rung orthopair fuzzy set}

Step 1: The decision-making matrix $X=\left(x_{i j}\right)_{n \times m}$ is transformed into the evaluation matrix $P=\left(p_{i j}\right)_{n \times m}$ in the same way shown in Table 3 .

Step 2: The relative weight of each criterion is calculated by (18), and it is shown in Table 9. 
Table 9. Relative weights

\begin{tabular}{|c|c|c|c|c|c|c|c|c|c|c|c|}
\hline & $c_{1}$ & $c_{2}$ & $c_{3}$ & $c_{4}$ & $c_{5}$ & $c_{6}$ & $c_{7}$ & $c_{8}$ & $c_{9}$ & $c_{10}$ & $c_{11}$ \\
\hline$\omega_{j r}$ & 1.000 & 0.605 & 0.660 & 0.500 & 0.240 & 0.246 & 0.278 & 0.351 & 0.179 & 0.531 & 0.499 \\
\hline
\end{tabular}

Step 3: Under each criterion, the relative dominance of the alternative $A_{i}$ over the others is determined by (19), and the results are exhibited in Table 10.

Table 10. Relative dominance for each criterion

\begin{tabular}{|c|c|c|c|c|c|c|c|c|c|c|c|}
\hline & $c_{1}$ & $c_{2}$ & $c_{3}$ & $c_{4}$ & $c_{5}$ & $c_{6}$ & $c_{7}$ & $c_{8}$ & $c_{9}$ & $c_{10}$ & $c_{11}$ \\
\hline$\Phi^{\prime}\left(a_{1}, a_{2}\right)$ & 0.222 & 0.138 & 0.104 & 0.113 & 0.105 & -0.984 & 0.105 & 0.085 & 0.068 & -0.318 & -0.610 \\
\hline$\Phi^{\prime}\left(a_{1}, a_{3}\right)$ & 0.266 & -0.549 & 0.227 & 0.153 & 0.137 & 0.067 & 0.062 & 0.136 & 0.055 & -0.244 & -0.652 \\
\hline$\Phi^{\prime}\left(a_{1}, a_{4}\right)$ & 0.180 & -0.650 & 0.2001 & 0.1645 & 0.064 & -1.142 & 0.117 & 0.093 & 0.076 & -0.531 & 0.117 \\
\hline
\end{tabular}

Note: Here $\theta=0.69$ in (19). The value is from the experiment conducted by Tversky and Kahneman (1992), and is used by most researchers.

Step 4: The dominance degree of alternative $A_{i}$ over the others is calculated by (15), and it is shown in Table 11.

Table 11. Prospect dominance degree of $A_{1}$

\begin{tabular}{|l|l|l|}
\hline$\delta^{\prime}\left(a_{1}, a_{2}\right)$ & $\delta^{\prime}\left(a_{1}, a_{3}\right)$ & $\delta^{\prime}\left(a_{1}, a_{4}\right)$ \\
\hline-0.9710 & -0.3422 & -1.3108 \\
\hline
\end{tabular}

Step 5: The overall dominance of each alternative is calculated by (16), and the result is exhibited in Table 12.

Table 12. Overall dominance

\begin{tabular}{|l|l|l|l|}
\hline$\eta^{\prime}\left(A_{1}\right)$ & $\eta^{\prime}\left(A_{2}\right)$ & $\eta^{\prime}\left(A_{3}\right)$ & $\eta^{\prime}\left(A_{4}\right)$ \\
\hline 1.0000 & 0.5242 & 0.0000 & 0.3282 \\
\hline
\end{tabular}

Step 6: It is known that there is $\eta^{\prime}\left(A_{1}\right)>\eta^{\prime}\left(A_{2}\right)>\eta^{\prime}\left(A_{4}\right)>\eta^{\prime}\left(A_{3}\right)$, so $A_{1} \succ A_{2} \succ A_{4} \succ A_{3}$. The alternative $A_{1}$ is recognized as the best option among the four green suppliers, whereas, $A_{3}$ is regarded as the worst one.

\subsection{Screening process by the novel TODIM with intuitionistic/Pythagorean fuzzy set}

In this section, we show the results of the novel TODIM with IFS and PFS separately. Considering the IFS and PFS are the special cases of q-ROFS, the detailed steps can refer to Section 4.2 , and the results are shown in Table 13. 
Table 13. Overall dominance with IFS/PFS

\begin{tabular}{|l|l|l|l|l|}
\hline Fuzzy environment & $\eta^{*}\left(A_{1}\right)$ & $\eta^{*}\left(A_{2}\right)$ & $\eta^{*}\left(A_{3}\right)$ & $\eta^{*}\left(A_{4}\right)$ \\
\hline IFS $(p=1)$ & 1.0000 & 0.6849 & 0.0000 & 0.3705 \\
\hline PFS $(p=2)$ & 1.0000 & 0.6721 & 0.0000 & 0.3796 \\
\hline
\end{tabular}

Note: Here, $\alpha=0.88, \beta=0.69$, and $\lambda=2.25$.

According to Table 13, the ranking results of novel TODIM with both IFS and PFS are $\eta^{*}\left(A_{1}\right)>\eta^{*}\left(A_{2}\right)>\eta^{*}\left(A_{4}\right)>\eta^{*}\left(A_{3}\right)$, that is, $A_{1} \succ A_{2} \succ A_{4} \succ A_{3}$. The alternative $A_{1}$ is considered to be the best choice among the four green suppliers, however, $A_{3}$ is the worst one with both IFS and PFS.

\subsection{Screening process by the extended TODIM with intuitionistic/Pythagorean fuzzy set}

In this section, we combine the extended TODIM with IFS and PFS. The basic steps are detailly depicted in Section 4.3. Here are the results in Table 14.

Table 14. Overall dominance with IFS/PFS

\begin{tabular}{|l|c|c|c|c|}
\hline & $\eta^{\prime}\left(A_{1}\right)$ & $\eta^{\prime}\left(A_{2}\right)$ & $\eta^{\prime}\left(A_{3}\right)$ & $\eta^{\prime}\left(A_{4}\right)$ \\
\hline IFS $(p=1)$ & 1.0000 & 0.5091 & 0.0000 & 0.3165 \\
\hline PFS $(p=2)$ & 1.0000 & 0.4853 & 0.0000 & 0.3273 \\
\hline
\end{tabular}

Note: Here, $\alpha=0.88, \beta=0.69$, and $\lambda=2.25$.

The ranking results obtained from extended TODIM with IFS and with PFS are the same. That is $\eta^{\prime}\left(A_{1}\right)>\eta^{\prime}\left(A_{2}\right)>\eta^{\prime}\left(A_{4}\right)>\eta^{\prime}\left(A_{3}\right)$, so $A_{1} \succ A_{2} \succ A_{4} \succ A_{3}$. The alternative $A_{1}$ is recognized as the best option among the four green suppliers, whereas, $A_{3}$ is regarded as the worst one both in the two different fuzzy environments.

\subsection{Screening process by the extended TOPSIS with q-rung orthopair fuzzy set}

To demonstrate the advantages of novel TODIM, the extension of TOPSIS with q-ROFS is proposed in this section. The classical TOPSIS proposed by Hwang and Yoon (1981) argues that the chosen alternative should be the one with the shortest distance to the positive-ideal solution and with the farthest distance to the negative ideal solution. The procedure of TOPSIS with q-ROFS is shown below.

Step 1: The original decision matrix $X=\left(x_{i j}\right)_{n \times m}$ is the same as Table 3. Since information represented by q-ROFN has no measurement units and scales, the normalized decision matrix is also the same as Table 3. The calculated weight is shown in section 4.1.

Step 2: Calculate the weighted normalized decision matrix. The weighted normalized evaluation matrix $K=\left[k_{i j}\right]_{n \times m}$ is determined by (21), and the results are shown in Table 15 .

$$
K=\left[k_{i j}\right]_{n \times m}=w_{j} \times x_{i j}, i=1,2, \cdots, n, j=1,2, \cdots, m .
$$


Table 15. The weighted normalized decision matrix

\begin{tabular}{|c|c|c|c|c|c|c|c|c|c|c|c|}
\hline & $c_{1}$ & $c_{2}$ & $c_{3}$ & $c_{4}$ & $c_{5}$ & $c_{6}$ & $c_{7}$ & $c_{8}$ & $c_{9}$ & $c_{10}$ & $c_{11}$ \\
\hline$A_{1}$ & $(0.161,0.004)$ & $(0.005,0.020)$ & $(0.071,0.039)$ & $(0.073,0.019)$ & $(0.033,0.008)$ & $(0.018,0.030)$ & $(0.043,0.004)$ & $(0.034,0.030)$ & $(0.016,0.011)$ & $(0.022,0.031)$ & $(0.046,0.023)$ \\
\hline$A_{2}$ & $(0.045,0,033)$ & $(0.027,0.052)$ & $(0.056,0.023)$ & $(0.043,0.011)$ & $(0.012,0.019)$ & $(0.028,0.012)$ & $(0.012,0.007)$ & $(0.021,0.022)$ & $(0.015,0.018)$ & $(0.009,0.027)$ & $(0.078,0.003)$ \\
\hline$A_{3}$ & $(0.047,0.090)$ & $(0.062,0.027)$ & $(0.005,0.115)$ & $(0.010,0.026)$ & $(0.007,0.034)$ & $(0.005,0.031)$ & $(0.038,0.011)$ & $(0.002,0.051)$ & $(0.018,0.017)$ & $(0.019,0.025)$ & $(0.087,0.003)$ \\
\hline$A_{4}$ & $(0.096,0.033)$ & $(0.059,0.056)$ & $(0.008,0.088)$ & $(0.004,0.007)$ & $(0.025,0.005)$ & $(0.035,0.007)$ & $(0.004,0.007)$ & $(0.012,0.027)$ & $(0.002,0.014)$ & $(0.055,0.044)$ & $(0.028,0.042)$ \\
\hline
\end{tabular}

Step 3: Get the positive ideal solution $A^{+}$and the negative ideal solution $A^{-}$according to (22) and (23) (Dagdeviren et al., 2009), where $J_{1}$ is associated with the benefit criterion, and $J_{2}$ is associated with the cost criterion. The comparison between $k_{i j}$ and $k_{i^{\prime} j}\left(i^{\prime}=1,2, \cdots, n\right.$, $\left.i \neq i^{\prime}\right)$ is determined by (2) and (3). The results are presented in Table 16.

$$
\begin{aligned}
& A^{+}=\left\{k_{1}^{+}, k_{2}^{+}, \cdots, k_{j}^{+}\right\}=\left\{\left(\max _{i} k_{i j} \mid j \in J_{1}\right),\left(\min _{i} k_{i j} \mid j \in J_{2}\right) \mid i=1,2, \cdots, n\right\} ; \\
& A^{-}=\left\{k_{1}^{-}, k_{2}^{-}, \cdots, k_{j}^{-}\right\}=\left\{\left(\min _{i} k_{i j} \mid j \in J_{1}\right),\left(\max _{i} k_{i j} \mid j \in J_{2}\right) \mid i=1,2, \cdots, n\right\} .
\end{aligned}
$$

Table 16. The positive ideal solution and negative ideal solution

\begin{tabular}{|c|c|c|c|c|c|c|c|c|c|c|c|}
\hline & $c_{1}$ & $c_{2}$ & $c_{3}$ & $c_{4}$ & $c_{5}$ & $c_{6}$ & $c_{7}$ & $c_{8}$ & $c_{9}$ & $c_{10}$ & $c_{11}$ \\
\hline$A^{+}$ & $(0.161,0.004)$ & $(0.062,0.027)$ & $(0.071,0.039)$ & $(0.073,0.019)$ & $(0.033,0.008)$ & $(0.035,0.007)$ & $(0.043,0.004)$ & $(0.034,0.030)$ & $(0.016,0.011)$ & $(0.055,0.044)$ & $(0.087,0.003)$ \\
\hline$A^{-}$ & $(0.047,0.090)$ & $(0.027,0.052)$ & $(0.005,0.115)$ & $(0.010,0.026)$ & $(0.007,0.034)$ & $(0.005,0.031)$ & $(0.004,0.007)$ & $(0.002,0.051)$ & $(0.002,0.014)$ & $(0.009,0.027)$ & $(0.028,0.042)$ \\
\hline
\end{tabular}

Step 4: Obtain the separation measures of each alternative from the proposed distance (24) and (25), where the hesitant degree is determined by (11). $D_{i}^{+}$represents the distance of alternative $A_{i}$ to the positive ideal solution and $D_{i}^{-}$is the distance to the negative ideal solution. The results are shown in Table 17.

$$
\begin{aligned}
& D_{i}^{+}=\sum_{j}^{m} d\left(k_{i j}, k_{i}^{+}\right)=\left(\frac{1}{3} \sum_{j}^{m}\left|\mu_{i j}-\mu_{i}^{+}\right|^{P}+\frac{1}{3} \sum_{j}^{m}\left|v_{i j}-v_{i}^{+}\right|^{P}+\frac{1}{3} \sum_{j}^{m}\left|\frac{v_{i j}-v_{i}^{+}}{\mu_{i j}-\mu_{i}^{+}}\left(\pi_{i j}^{\prime}-\pi_{i}^{+^{\prime}}\right)^{P}\right|\right)^{1 / P} ; \\
& D_{i}^{-}=\sum_{j}^{m} d\left(k_{i j}, k_{i}^{-}\right)=\left(\frac{1}{3} \sum_{j}^{m}\left|\mu_{i j}-\mu_{i}^{-}\right|^{P}+\frac{1}{3} \sum_{j}^{m}\left|v_{i j}-v_{i}^{-}\right|^{P}+\frac{1}{3} \sum_{j}^{m}\left|\frac{v_{i j}-v_{i}^{-}}{\mu_{i j}-\mu_{i}^{-}}\left(\pi_{i j}^{\prime}-\pi_{i}^{-^{\prime}}\right)^{P}\right|\right)^{1 / P} .
\end{aligned}
$$

Table 17. Separation measures of each alternative

\begin{tabular}{|c|c|c|c|c|}
\hline & $A_{1}$ & $A_{2}$ & $A_{3}$ & $A_{4}$ \\
\hline$D_{i}^{+}$ & 0.0704 & 0.1500 & 0.2151 & 0.1710 \\
\hline$D_{i}^{-}$ & 0.2326 & 0.1595 & 0.0751 & 0.1319 \\
\hline
\end{tabular}

Step 5: Acquire the relative closeness coefficient by (26). Then, they are presented in Table 18.

$$
C_{i}^{\star}=\frac{D_{i}^{-}}{D_{i}^{+}+D_{i}^{-}}, i=1,2, \cdots, n .
$$


Table 18. Ranking results obtained from TOPSIS

\begin{tabular}{|l|c|c|c|c|}
\hline \multicolumn{1}{|c|}{ Distance type } & $A_{1}$ & $A_{2}$ & $A_{3}$ & $A_{4}$ \\
\hline$C_{i}^{*}(p=1)$ & 0.7678 & 0.5154 & 0.2587 & 0.4355 \\
\hline$C_{i}^{*}(p=2)$ & 0.8492 & 0.5115 & 0.1685 & 0.3659 \\
\hline
\end{tabular}

According to the results in Table 18, the rank of alternatives are: $A_{1} \succ A_{2} \succ A_{4} \succ A_{3}$. Then, $A_{1}$ is the best supplier selected by q-rung orthopair fuzzy TOPSIS, while $A_{3}$ is the last choice among the four green suppliers.

\section{Comparative analysis}

To evaluate the performance of the novel TODIM, this section presents the sample analysis, sensitivity analysis, and simulation analysis. The effectiveness of the novel TODIM is well explained through these three perspectives.

\subsection{A sample analysis}

With different fuzzy sets, the overall dominance and the relative closeness coefficients derived from the extensions of corresponding classical/novel TODIM and TOPSIS are separately shown in Table 19. Then, a comparative analysis is provided in this section.

Table 19. The results of 14 combinations

\begin{tabular}{|c|c|c|c|c|c|c|c|c|c|c|c|c|c|c|c|c|c|c|}
\hline Method & \multicolumn{6}{|c|}{ The extension of classical TODIM } & \multicolumn{6}{|c|}{ The novel TODIM } & \multicolumn{6}{|c|}{ The extension of TOPSIS } \\
\hline Fuzzy sets & \multicolumn{2}{|c|}{$\begin{array}{l}q=1 \\
\text { (IFS) }\end{array}$} & \multicolumn{2}{|c|}{$\begin{array}{l}q=2 \\
(\mathrm{PFS})\end{array}$} & \multicolumn{2}{|c|}{$\begin{array}{c}q=3 \\
(q-\mathrm{ROFS})\end{array}$} & \multicolumn{2}{|c|}{$\begin{array}{l}q=1 \\
\text { (IFS) }\end{array}$} & \multicolumn{2}{|c|}{$\begin{array}{l}q=2 \\
(\mathrm{PFS})\end{array}$} & \multicolumn{2}{|c|}{$\begin{array}{c}q=3 \\
(q-\mathrm{ROFS})\end{array}$} & \multicolumn{2}{|c|}{$\begin{array}{l}q=1 \\
\text { (IFS) }\end{array}$} & \multicolumn{2}{|c|}{$\begin{array}{l}q=2 \\
(\mathrm{PFS})\end{array}$} & \multicolumn{2}{|c|}{$\begin{array}{c}q=3 \\
(q-\mathrm{ROFS})\end{array}$} \\
\hline Dista & $=1$ & $p=2$ & $p=1$ & $p=2$ & $p=1$ & $p=2$ & $p=1$ & $p=2$ & $p=1$ & $p=2$ & $p=1$ & $p=2$ & $p=1$ & $p=2$ & $p=1$ & $p=2$ & $p=1$ & $p=2$ \\
\hline$\eta\left(A_{1}\right)$ & 00 & 1.000 & 000 & 000 & 000 & 1.000 & 1.000 & 1.000 & 1.000 & 1.000 & 1.000 & 1.000 & 0.771 & 0.783 & 0.769 & 0.844 & 0.768 & 0.849 \\
\hline$\eta\left(A_{2}\right)$ & 9 & 2 & 5 & 4 & 4 & 73 & 34 & 24 & 72 & 5 & 0.699 & 0 & 12 & 75 & 0.533 & 0.566 & 15 & 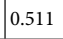 \\
\hline$\eta\left(A_{3}\right)$ & 000 & 0.000 & 00 & 00 & 000 & 0.000 & 0.000 & 0.000 & 0.000 & 0.000 & 0.000 & 0.000 & 0.255 & 0.257 & 0.258 & 0.178 & 0.259 & 0.169 \\
\hline$\eta\left(A_{4}\right)$ & 316 & 0.247 & 0.327 & 0.248 & 0.328 & 0.256 & 0.371 & 0.267 & 0.380 & 0.268 & 0.385 & 0.273 & 0.441 & 0.409 & 0.439 & 0.404 & 0.435 & 0.366 \\
\hline$\Delta\left(\eta\left(A_{2}\right)-\eta\left(A_{4}\right)\right)$ & 193 & 0.204 & 0.158 & 0.175 & 0.196 & 0.216 & 0.314 & 0.357 & 0.292 & 0.337 & 0.314 & 0.360 & 0.171 & 0.266 & 0.094 & 0.162 & 0.080 & 0.14 \\
\hline
\end{tabular}

All 18 different types of combinations haves concluded that $A_{1}$ is the best choice and $A_{3}$ is the last one. As for the comparison of extended TODIM and novel TODIM, we can conclude that with the same fuzzy set and the same type of distance, the overall dominances of $A_{2}$ and $A_{4}$ derived from the novel TODIM have greater values than the extended one. Besides, the difference of overall dominance between $A_{2}$ and $A_{4}$ derived by the novel TODIM is larger than the extended ones with the same fuzzy set and the same type of distance. Therefore, it indicates that the novel TODIM is better at distinguishing the intermediaries $\left(A_{2}\right.$ and $\left.A_{4}\right)$ in decision-making process, especially when these two companies are similar to each other. 
As for the comparison of the novel TODIM and the extended TOPSIS, the relative closeness coefficients between $A_{2}$ and $A_{4}$ obtained from the extended TOPSIS is significantly smaller than the dominance degree between $A_{2}$ and $A_{4}$ obtained from the novel TODIM. More than this, as for the ranking results of $A_{2}$ and $A_{4}$ under IFS, the results of adopting the extended TOPSIS are completely different from those of taking novel TODIM, which indicates that the extended TOPSIS is difficult to make a decision when faced with two similar companies under IFS. Also, the extended TOPSIS has not made the same choice as the novel TODIM when the information set is not complicated enough to cover a wider range of information. In this case, the extended TOPSIS has not reached a consistent choice with the novel TODIM until it is expanded to the PFS. Only with the increasing information of messages, the extended TOPSIS gradually has the ability to distinguish two intermediary companies. In contrast, the novel TODIM has this off-key ability incipiently when the amount of information is trivial, which greatly illustrates that the novel TODIM not only has the superior ability in solving the fuzziness of two middle choices but also makes consistent choices with tiny informativeness. Meanwhile, we can find that for a specific method with the same type of distance, the overall dominance degrees or the relative closeness coefficients required from TODIM or TOPSIS methods have larger values with the increasing complexity information.

\subsection{Sensitivity analysis}

$\lambda$ is the only parameter that exists in both the novel TODIM (seen in (14)) and the extended TODIM (seen in (19)). It can be a powerful implement to test the stability of those two models by observing the fluctuation of results with the change of this parameter in those two methods. Then, the advantages of the novel TODIM are thoroughly examined by analyzing the effect of the parameter change on the results. Therefore, in this section, we conduct 1000 sensitivity tests by using the same example in section 4.2 .

By adding one-thousand-th to the value of $\lambda$ each time in a certain range $(1.25<\lambda$ $\leq 2.25$ ), the sensitivity results with the novel TODIM and with the extended TODIM are obtained respectively. Besides, no matter how the parameter $\lambda$ changes, the alternatives $A_{1}$ and $A_{3}$ remain to be the best and the last option all the time. Moreover, with different values of the parameter $\lambda$, the overall dominance degrees $\eta\left(a_{i}\right)$ of $A_{1}$ and $A_{3}$ are correspondingly fixed to be 1 and 0 , which is determined by the characteristic of TODIM itself. Hence, to show the robustness of novel TODIM when compared with extended one, we present an overall sensitivity analysis by integrating the IFS, PFS, and q-ROFS into these two methods, respectively, which aims to observe the changes of overall dominance degrees of intermediary alternatives $A_{2}$ and $A_{4}$. The graphs of the change trend of both the overall dominance degrees of $A_{2}$ and $A_{4}$ are presented in Figure 1 and Figure 2, respectively.

From both Figure 1 and Figure 2, the direct evidence has shown the robustness of the proposed novel TODIM because the overall dominance degrees obtained from the novel TODIM changes in a more stable trend than those from the extended one. As for alternatives $A_{2}$ and $A_{4}$, the slopes with the same method when varying the fuzzy set among IFS, PFS and q-ROFS have almost no difference. For example, the slope of the novel TODIM keeps nearly a straight line with the change of fuzzy sets. On the other hand, by comparing 


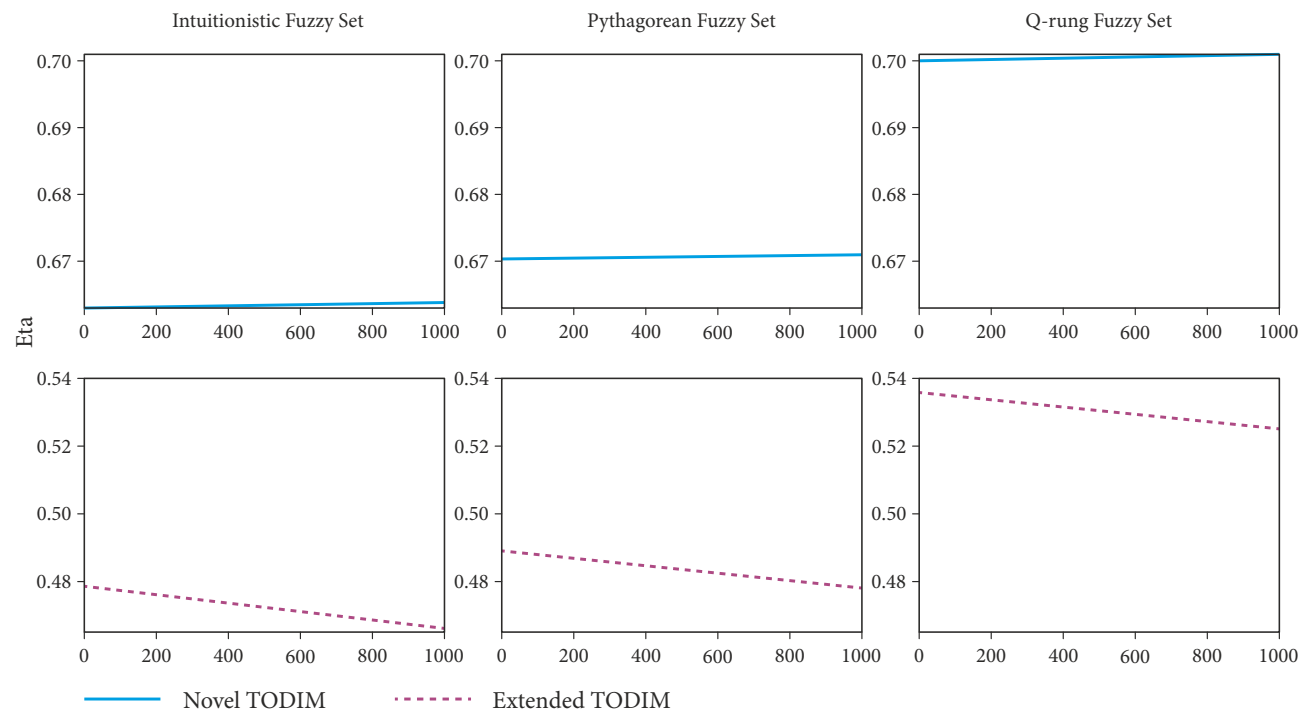

Figure 1 . The sensitivity analysis results of $A_{2}(1.25<\lambda \leq 2.25)$


Figure 2. The sensitivity analysis results of $A_{4}(1.25<\lambda \leq 2.25)$

the slopes of the extended TODIM with the ones of the novel TODIM under the same fuzzy set, it is easy to observe that the novel TODIM is more stable. That is, the choice of methods rather than the selection of information fuzzy set is proved to be the factor that influences the robustness of results. This promises the reasonableness of sensitivity outcomes. Also, the comparison shows the advantages of the novel TODIM. 
To illustrate the results numerically, we calculate the standard deviation of the results derived by the novel TODIM and the extended TODIM with q-ROFS. The result of the novel method is remarkably lower than the extended one $(0.000189 / 0.003092 ; 0.000038 / 0.000628)$. The standard deviation of the two methods differs by a factor of ten. That is also why the straight lines obtained by the novel method look flat when drawn at the same scale in Figure 1 and Figure 2, while the results of the extended method look like steep straight lines. Apparently, this is a strong proof of the stability of the novel TODIM. Subsequently, we conclude that the novel TODIM outperforms the extended one.

Moreover, the overall dominance degrees vary a lot with different fuzzy sets. More complicated fuzzy sets like q-ROFS promise a bigger value of overall dominance degree than those simple sets, which strongly proves that the fuzzy sets play a role in determining the results. Furthermore, the 1000 sets of sensitivity analysis tests generated in this section further demonstrate two conclusions from a sample analysis: (i) Compared to extended TODIM, the overall dominance degrees obtained by the novel TODIM have greater values; (ii) Apart from that, the difference of overall dominance degrees between $A_{2}$ and $A_{4}$ derived by extended TODIM is smaller than the one by the novel TODIM with the same type of distance and the same fuzzy set. The latter one also shows the advantages of novel TODIM, which is based on the fact that the more significant difference between $A_{2}$ and $A_{4}$, the better distinguish between the intermediate companies will be. These differences mainly lie in the disparate dominance function in the proposed novel TODIM and the extended TODIM. The novel TODIM aligns with the original idea of PT by adjusting the different risk attitudes for the gains or losses and by considering the transformed weighting function. Thereby, the novel TODIM is more reasonable in reality.

\subsection{Simulation analysis}

Since the illustration of one sample in section 5.1 is not convincing enough, multi-sample simulation analysis is carried out to testify further the logic connection among the research objects, which also proves the advantages of novel TODIM by comparing it with the extension of classical TODIM. Firstly, 1000 sets of random numbers are generated to represent the original evaluation information, and there is $0 \leq \mu(x)+v(x) \leq 1$. Then, six experiments are formed by calculating the coincident quantities. For example, experiment (1) presents the overlaps selection results by applying the novel TODIM proposed in section 4.3 ( $q=3$ q-ROFS) and the extended one proposed in section 4.4 ( $q=1$ IFS). Based on this, the other five experiments are also carried out. The results are shown in Table 20. All of them are further divided into various experimental groups, such as experimental group (1) and (2) which can be abbreviated as $(1,2)$, and similarly to $(3,4)(5,6)(1,3,5)(2,4,6)$. It is a convenient way to prove the effectiveness and the prominent advantages of integrating q-ROFS into the MCDM process.

From the experimental group $(1,2)$, we can get that, when fixed the second fuzzy information like q-ROFS $(q=3)$, the result based on IFS $(q=1)$ has a lower degree of overlap than that based on PFS $(q=2)$. This is mainly because the closer of the two kinds of fuzzy information is, the more similar the evaluation results will be. Complicated fuzzy information $(q=2)$ can cover a wider range of information than the simple one $(q=1)$. Therefore, 
Table 20 . The coincident quantity of 1000 samples simulation analysis

\begin{tabular}{|c|c|c|c|}
\hline Items & Experiment & The extension of classical TODIM & The novel TODIM \\
\hline$(1)$ & $q=1$ vs $q=3$ & 521 & 541 \\
\hline$(2)$ & $q=2$ vs $q=3$ & 774 & 791 \\
\hline$(3)$ & $q=1$ vs $q=4$ & 481 & 503 \\
\hline$(4)$ & $q=2$ vs $q=4$ & 673 & 692 \\
\hline$(5)$ & $q=1$ vs $q=6$ & 439 & 473 \\
\hline$(6)$ & $q=2$ vs $q=6$ & 578 & 590 \\
\hline
\end{tabular}

Note: The results are generated under the condition with the new distance and parameter $p=1$.

when comparing with q-ROFS $(q=3)$, the degree of coincidence of the former one $(q=2)$ is bigger than the later one $(q=1)$. In other words, we will get a bigger number of matches when two fuzzy sets are more contiguous. Furthermore, experimental groups containing (3, $4)$ and $(5,6)$ also get the same conclusion.

The above conclusion can also be obtained from the other experimental groups, including $(1,3,5)$ and $(2,4,6)$, which fix the first fuzzy set and change the other comparative fuzzy set. Taking the experiment group $(1,3,5)$ as an example, which keeps the former fuzzy set unchanged as IFS $(q=1)$, it shows a pattern that the number of coincidences decreases when the other fuzzy set is more complicated. The reason for this phenomenon mainly lies in that a more complicated fuzzy set is better at handling the larger amount of information. Also, it is capable of refining and processing information acquired from the real world. Therefore, the number of matches decreases.

From the above analysis about the different fuzzy sets, it can be seen that no matter which method is adopted, the comparison results about the fuzzy sets are consistent. However, regarding the coincidence numbers, the results of the novel TODIM are larger than those of the extended ones.

\section{Conclusions}

As the complexity of fuzzy information increases, psychological influence can no longer be ignored. In this article, we propose a new algorithm to calculate the distances of q-ROFNs by concerning the herd mentality. Also, the different risk attitudes for gains or losses and the transformed weighting function of DMs in the decision-making process should be considered. Therefore, to comprehensively reflect the psychological behavior of DMs, a novel TODIM based on both the value function and the weighting function in PT is constructed to overcome the downside of a simple extension of TODIM. Moreover, in this paper, we develop the novel TODIM and the extended TODIM with several different types of fuzzy sets like IFS and PFS to show the advantages of the proposed novel TODIM with q-ROFS.

According to the case study about the pork supplier chain with the proposed index system (PCEM) and various sample analyses including sample analysis, sensitivity analysis as well as simulation analysis, we conclude that the novel TODIM has been demonstrated to be more stable and more capable of distinguishing the middle two companies $\left(A_{2}\right)$ and $\left(A_{4}\right)$. 
The dominance degree from the novel TODIM has a larger value than the one from the extended one. Besides, the proximity of two fuzzy information ensures a bigger coincident number of decision choices. According to the comparison of the novel TODIM and the extended TOPSIS, the former one always effectively solves the ambiguity of two intermediate choices, and shows extraordinary abilities in resisting the influence of distance parameter.

On the other hand, this study also provides a valuable research direction to consider more psychological states of DMs in both distance measure and decision-making model. Meanwhile, the novel TODIM can be extended to the other more complicated fuzzy environments and more perspective fuzzy environments can also be integrated into various methods to solve MCDM problems. Furthermore, group decision making (GDM) (Liu et al., 2019; Pérez et al., 2010), especially the consensus problem in GDM (Del Moral et al., 2018), is a hot topic in recent years. Hence, the TODIM with GDM and the consensus model with the psychological characteristics of DMs will be considered in our future work.

\section{Acknowledgements}

The authors would like to acknowledge the financial support by the Fundamental Research Funds for the Central Universities (\#JBK2001043, and \#JBK190969), the FEDER funds provided in the National Spanish project PID2019-103880RB-I00 and also it has been partially supported by grant from the National Natural Science Foundation of China (\#71910107002).

\section{References}

Atanassov, K. T. (1986). Intuitionistic fuzzy sets. Fuzzy Sets and Systems, 20, 87-96. https://doi.org/10.1016/S0165-0114(86)80034-3

Atanassov, K. T., \& Gargov, G. (1989). Interval valued intuitionistic fuzzy sets. Fuzzy Sets and Systems, 31(3), 343-349. https://doi.org/10.1016/0165-0114(89)90205-4

Awasthi, A., Chauhan, S. S., \& Goyal, S. K. (2010). A fuzzy multicriteria approach for evaluating environmental performance of suppliers. International Journal of Production Economics, 126(2), 370378. https://doi.org/10.1016/j.ijpe.2010.04.029

Awasthi, A., Govindan, K., \& Gold, S. (2018). Multi-tier sustainable global supplier selection using a fuzzy AHP-VIKOR based approach. International Journal of Production Economics, 195, 106-117. https://doi.org/10.1016/j.ijpe.2017.10.013

Bai, C., \& Sarkis, J. (2010a). Green supplier development: Analytical evaluation using rough set theory. Journal of Cleaner Production, 18, 1200-1210. https://doi.org/10.1016/j.jclepro.2010.01.016

Bai, C., \& Sarkis, J. (2010b). Integrating sustainability into supplier selection with grey system and rough set methodologies. International Journal of Production Economics, 124(1), 252-264. https://doi.org/10.1016/j.ijpe.2009.11.023

Bala, A., Muñoz, P., Rieradevall, J., \& Ysern, P. (2008). Experiences with greening suppliers. The Universitat Autònoma de Barcelona. Journal of Cleaner Production, 16(15), 1610-1619. https://doi.org/10.1016/j.jclepro.2008.04.015

Bin, L., \& Hong-jun, L. (2010). A research on supplier assessment indices system of green purchasing. In 2010 International Conference on Measuring Technology and Mechatronics Automation, 1, 314-317. IEEE. https://doi.org/10.1109/ICMTMA.2010.694 
Buyukozkan, G., \& Cifci, G. (2011). A novel fuzzy multi-criteria decision framework for sustainable supplier selection with incomplete information. Computers in Industry, 62(2), 164-174. https://doi.org/10.1016/j.compind.2010.10.009

Buyukozkan, G., \& Cifci, G. (2012). A novel hybrid MCDM approach based on fuzzy DEMATEL, fuzzy ANP and fuzzy TOPSIS to evaluate green suppliers. Expert Systems with Applications, 39(3), 3000-3011. https://doi.org/10.1016/j.eswa.2011.08.162

Chatterjee, K., Pamucar, D., \& Zavadskas, E. K. (2018). Evaluating the performance of suppliers based on using the R'AMATEL-MAIRCA method for green supply chain implementation in electronics industry. Journal of Cleaner Production, 184, 101-129. https://doi.org/10.1016/j.jclepro.2018.02.186

Chen, K. L., Yeh, C. C., \& Huang, J. C. (2014). Supplier selection using a hybrid model for 3C industry. Journal of Business Economics and Management, 15(4), 631-645.

https://doi.org/10.3846/16111699.2013.807870

Chen, Y. S., Lai, S. B., \& Wen, C. T. (2006). The influence of green innovation performance on corporate advantage in Taiwan. Journal of Business Ethics, 67(4), 331-339. https://doi.org/10.1007/s10551-006-9025-5

Chiou, T. Y., Chan, H. K., Lettice, F., \& Chung, S. H. (2011). The influence of greening the suppliers and green innovation on environmental performance and competitive advantage in Taiwan. Transportation Research Part E: Logistics and Transportation Review, 47(6), 822-836.

https://doi.org/10.1016/j.tre.2011.05.016

Dagdeviren, M., Yavuz, S., \& Kilinc, N. (2009). Weapon selection using the AHP and TOPSIS methods under fuzzy environment. Expert Systems with Applications, 36(4), 8143-8151.

https://doi.org/10.1016/j.eswa.2008.10.016

Del Moral, M. J., Chiclana, F., Tapia, J. M., \& Herrera-Viedma, E. (2018). A Comparative study on consensus measures in group decision making. International Journal of Intelligent Systems, 33(8), 1624-1638. https://doi.org/10.1002/int.21954

$\mathrm{Du}$, W. S., \& Hu, B. Q. (2017). Dominance-based rough fuzzy set approach and its application to rule induction. European Journal of Operational Research, 261(2), 690-703.

https://doi.org/10.1016/j.ejor.2016.12.004

Fallahpour, A., Olugu, E. U., Musa, S. N., Wong, K. Y., \& Noori, S. (2017). A decision support model for sustainable supplier selection in sustainable supply chain management. Computers and Industrial Engineering, 105, 391-410. https://doi.org/10.1016/j.cie.2017.01.005

Fan, Z. P., Zhang, X., Chen, F. D., \& Liu, Y. (2013). Extended TODIM method for hybrid multiple attribute decision making problems. Knowledge-Based Systems, 42, 40-48.

https://doi.org/10.1016/j.knosys.2012.12.014

Grisi, R. M., Guerra, L., \& Naviglio, G. (2010). Supplier performance evaluation for green supply chain management. In Business Performance Measurement and Management (pp. 149-163). Springer. https://doi.org/10.1007/978-3-642-04800-5_10

Gomes, L. F. A. M., \& Lima, M. M. P. P. (1991). TODIM: basic and application to multicriteria ranking of projects with environmental impacts. Foundations of Computing and Decision Sciences, 16(4), 113-127.

Gomes, L. F. A. M., \& Lima, M. M. P. P. (1992). From modeling individual preferences to multicriteria ranking of discrete alternatives: A look at prospect theory and the additive difference model. Foundations of Computing and Decision Sciences, 17(3), 171-184.

Hsu, C. W., \& Hu, A. H. (2009). Applying hazardous substance management to supplier selection using analytic network process. Journal of Cleaner Production, 17(2), 255-264. https://doi.org/10.1016/j.jclepro.2008.05.004

Hsu, C. W., Kuo, T. C., Chen, S. H., \& Hu, A. H. (2013). Using DEMATEL to develop a carbon management model of supplier selection in green supply chain management. Journal of Cleaner Production, 56, 164-172. https://doi.org/10.1016/j.jclepro.2011.09.012 
Humphreys, P., McCloskey, A., McIvor, R., Maguire, L., \& Glackin, C. (2006). Employing dynamic fuzzy membership functions to assess environmental performance in the supplier selection process. International Journal of Production Research, 44(12), 2379-2419. https://doi.org/10.1080/00207540500357476

Hwang, C. L., \& Yoon, K. (1981). Methods for multiple attribute decision making. In Lecture Notes in Economics and Mathematical Systems: Vol. 186. Multiple Attribute Decision Making (pp. 58-191). Springer, Berlin, Heidelberg. https://doi.org/10.1007/978-3-642-48318-9_3

Kang, H. Y., Lee, A. H. I., \& Yang, C. Y. (2012). A fuzzy ANP model for supplier selection as applied to IC packaging. Journal of Intelligent Manufacturing, 23(5), 1477-1488.

https://doi.org/10.1007/s10845-010-0448-6

Kannan, D., Jabbour, A. B. L. D. S., \& Jabbour, C. J. C. (2014). Selecting green suppliers based on GSCM practices: Using fuzzy TOPSIS applied to a Brazilian electronics company. European Journal of Operational Research, 233(2), 432-447. https://doi.org/10.1016/j.ejor.2013.07.023

Klassen, R. D. (1993). The integration of environmental issues into manufacturing: Toward an interactive open-systems model. Production and Inventory Management Journal, 34(1), 82-88.

Koplin, J., Seuring, S., \& Mesterharm, M. (2007). Incorporating sustainability into supply management in the automotive industry - the case of the Volkswagen AG. Journal of Cleaner Production, 15(11-12), 1053-1062. https://doi.org/10.1016/j.jclepro.2006.05.024

Krohling, R. A., Pacheco, A. G. C., \& Siviero, A. L. T. (2013). IF-TODIM: An intuitionistic fuzzy TODIM to multi-criteria decision making. Knowledge-Based Systems, 53, 142-146. https://doi.org/10.1016/j.knosys.2013.08.028

Kuo, R. J., Wang, Y. C., \& Tien, F. C. (2010). Integration of artificial neural network and MADA methods for green supplier selection. Journal of Cleaner Production, 18(12), 1161-1170.

https://doi.org/10.1016/j.jclepro.2010.03.020

Lee, A. H., Kang, H. Y., Hsu, C. F., \& Hung, H. C. (2009). A green supplier selection model for hightech industry. Expert systems with applications, 36(4), 7917-7927.

https://doi.org/10.1016/j.eswa.2008.11.052

Liang, D. C., Zhang, Y. R. J., Xu, Z. S., \& Jamaldeen, A. (2019). Pythagorean fuzzy VIKOR approaches based on TODIM for evaluating internet banking website quality of Ghanaian banking industry. Applied Soft Computing, 78, 583-594. https://doi.org/10.1016/j.asoc.2019.03.006

Liang, H. M., Wang, X., \& Dong, Y. C. (2018). A prospect theory-based method for fusing the individual preferenceapproval structures in group decision making. Computers \& Industrial Engineering, 117, 237-248. https://doi.org/10.1016/j.cie.2018.01.001

Liu, P. D., \& Liu, J. L. (2018). Some q-Rung orthopai fuzzy bonferroni mean operators and their application to multi-attribute group decision making. International Journal of Intelligent Systems, 33(2), 315-347. https://doi.org/10.1002/int.21933

Liu, Y. T., Dong, Y. C., Liang, H. M., Chiclana, F., \& Herrera-Viedma, E. (2019). Multiple attribute strategic weight manipulation with minimum cost in a group decision making context with interval attribute weights information. IEEE Transactions on Systems Man and Cybernetics: Systems, 40(10), 1981-1992. https://doi.org/10.1109/TSMC.2018.2874942

Min, H., \& Galle, W. P. (2001). Green purchasing practices of US firms. International Journal of Operations \& Production Management, 21(9), 1222-1238. https://doi.org/10.1108/EUM0000000005923

Mishra, A. R., \& Rani, P. (2018). Biparametric information measures-based TODIM technique for interval-valued intuitionistic fuzzy environment. Arabian Journal for Science and Engineering, 43(6), 3291. https://doi.org/10.1007/s13369-018-3069-6

Peng, X. D., Dai, J. G., \& Garg, H. (2018). Exponential operation and aggregation operator for q-rung orthopair fuzzy set and their decision-making method with a new score function. International Journal of Intelligent Systems, 33(11), 2255-2282. https://doi.org/10.1002/int.22028 
Pérez, I. J., Cabrerizo, F. J., \& Herrera-Viedma, E. (2010). A mobile decision support system for dynamic group decision making problems. IEEE Transactions on Systems Man and Cybernetics Part A: Systems and Humans, 40(6), 1244-1256. https://doi.org/10.1109/TSMCA.2010.2046732

Qin, J. D., Liu, X. W., \& Pedrycz, W. (2015). An extended VIKOR method based on prospect theory for multiple attribute decision making under interval type-2 fuzzy environment. Knowledge-Based Systems, 86, 115-130. https://doi.org/10.1016/j.knosys.2015.05.025

Ren, P. J., Xu, Z. S., \& Gou, X. J. (2016). Pythagorean fuzzy TODIM approach to multi-criteria decision making. Applied Soft Computing, 42, 246-259. https://doi.org/10.1016/j.asoc.2015.12.020

Shaw, K., Shankar, R., Yadav, S. S., \& Thakur, L. S. (2012). Supplier selection using fuzzy AHP and fuzzy multi-objective linear programming for developing low carbon supply chain. Expert Systems with Applications, 39(9), 8182-8192. https://doi.org/10.1016/j.eswa.2012.01.149

Szmidt, E., \& Kacprzyk, J. (2000). Distances between intuitionistic fuzzy sets. Fuzzy Sets and Systems, 114(3), 505-518. https://doi.org/10.1016/S0165-0114(98)00244-9

Tam, M. C. Y., \& Tummala, V. M. R. (2001). An application of the AHP in vendor selection of a telecommunications system. Omega, 29(2), 171-182. https://doi.org/10.1016/S0305-0483(00)00039-6

Tian, X. L., Kou, G., \& Zhang, W. K. (2020). Geographic distance, venture capital and technological performance: Evidence from chinese enterprises. Technological Forecasting and Social Change, 158, 120155. https://doi.org/10.1016/j.techfore.2020.120155

Tian, X. L., Xu, Z. S., \& Gu, J. (2019). An extended TODIM based on cumulative prospect theory and its application in venture capital. Informatica, 30(2), 413-429. https://doi.org/10.15388/Informatica.2019.212

Trapp, A. C., \& Sarkis, J. (2016). Identifying Robust portfolios of suppliers: A sustainability selection and development perspective. Journal of Cleaner Production, 112(3), 2088-2100. https://doi.org/10.1016/j.jclepro.2014.09.062

Tversky, A., \& Kahneman, D. (1992). Advances in prospect theory: Cumulative representation of uncertainty. Journal of Risk and Uncertainty, 5(4), 297-323. https://doi.org/10.1007/BF00122574

Wang, R., \& Li, Y. L. (2018). A novel approach for green supplier selection under a q-rung orthopair fuzzy environment. Symmetry, 10, 1-28. https://doi.org/10.3390/sym10120687

Xu, Y., Shang, X. P., Wang, J., Wu, W., \& Huang, H. Q. (2018). Some q-rung dual hesitant fuzzy heronian mean operators with their application to multiple attribute group decision-making. Symmetry, 10(10), 1-25. https://doi.org/10.3390/sym10100472

Yazdani, M., Zolfani, S. H., \& Zavadskas, E. K. (2016). New integration of MCDM methods and QFD in the selection of green suppliers. Journal of Business Economics and Management, 17(6), 1097-1113. https://doi.org/10.3846/16111699.2016.1165282

Yager, R. R. (2013). Pythagorean fuzzy subsets. Paper presented at IFSA World Congress and NAFIPS Annual Meeting (IFSA/NAFIPS), Edmonton, Canada. https://doi.org/10.1109/IFSA-NAFIPS.2013.6608375

Yager, R. R. (2017). Generalized orthopair fuzzy sets. IEEE Transactions on Fuzzy Systems, 25(5), 12221230. https://doi.org/10.1109/TFUZZ.2016.2604005

Yu, Q., \& Hou, F. (2016). An approach for green supplier selection in the automobile manufacturing industry. Kybernetes, 45(4), 571-588. https://doi.org/10.1108/K-01-2015-0034 